Supporting Information

\title{
From paramagnetic to superparamagnetic ionic liquid/poly(ionic liquid): the effect of $\pi-\pi$ stacking interaction
}

Xiaoliang Yu, Xiaoyan Yuan*, Yunhui Zhao, and Lixia Ren*

School of Materials Science and Engineering, Tianjin Key Laboratory of Composite and

Functional Materials, Tianjin University, Tianjin 300350, China

E-mail:yuanxy@tju.edu.cn; 1xren@tju.edu.cn 


\section{Contents}

General experiment

1. Synthesis of the MILs and PMILs

2. NMR analyses of all the compounds

3. Kinetics for TMBBDI[Cl] polymerization

4. GPC of PTMBBDI[Cl]

5. Mass spectra of compounds

6. Raman spectra

7. Thermal and optical property

8. XRD spectra and molecule structure

9. Magnetic behavior

References 


\section{General experiment}

Materials 3a,4,7,7a-Tetrahydro-1H-4,7-methanoisoindole-1,3(2H)-dione (98\%) was purchased from Huateng Technology; 1,4-dibromobutane (98\%) and 1,10-dibromodecane (99\%) were purchased from Damas-Beta; 4,4'-biphenol (99\%) and $\mathrm{N}$-methyl imidazole (99\%) were purchased from Heowns Biochem; potassium iodide (KI) (99\%), ethyl vinyl ether (EVE) (98\%) and ferroferric oxide (99\%, metals basis, $20 \mathrm{~nm}$, spherical) were purchased from Aladdin Industrial. Ionic exchange resin (IRA-400Cl) was purchased from Alfa-Aesar. All of these reagents were used as received without further purification. The Grubbs third generation catalyst (G3) was prepared according to the procedures reported. ${ }^{1,2}$ All the solvents ( $N, N$-Dimethylformamide (DMF), dichloromethane (DCM), tetrahydrofuran (THF), acetone, hydrochloric acid ( $\mathrm{HCl}$ ), petroleum ether, ethyl acetate and methanol) used were purchased from Yuanli Chemical and dried before usage if necessary. All non-aqueous reactions were carried out in oven-dried glassware under nitrogen atmosphere. Column chromatograph was performed on silica gel (200-300 mesh).

Instrumentation ${ }^{1} \mathrm{H}$ and ${ }^{13} \mathrm{C}$ NMR spectra were recorded on a VARIAN INOVA $500 \mathrm{MHz}$ spectrometer $\left({ }^{1} \mathrm{H}=500 \mathrm{MHz},{ }^{13} \mathrm{C}=126 \mathrm{MHz}\right)$ and a Bruker AVANCE III 400MHz spectrometer $\left({ }^{1} \mathrm{H}=400 \mathrm{MHz},{ }^{13} \mathrm{C}=101 \mathrm{MHz}\right)$ at $298 \mathrm{~K}$. Chemical shifts in ${ }^{1} \mathrm{H}$ NMR spectra were reported in ppm on the $\delta$ scale from an internal standard of TMS. The following abbreviations were used to explain the multiplicities in ${ }^{1} \mathrm{H}$ NMR: $\mathrm{s}=$ singlet, $\mathrm{d}$ 
$=$ doublet, $\mathrm{t}=$ triplet, $\mathrm{q}=$ quartet, $\mathrm{dd}=$ doublet of doublets, $\mathrm{ddd}=$ doublet of doublet of doublets, $\mathrm{m}=$ multiplet, $\mathrm{br}=$ broad. Mass spectra were conducted on Bruker-1290 UPLC/ micrOTOF-Q II or Bruker-Autoflex tof/tofIII-MALDI-TOF instruments. Raman spectrum was carried out on Renishaw-inVia reflex using a $785 \mathrm{~nm}$ excitation wavelength. Polydispersity index $(\mathrm{PDI}=\mathrm{Mw} / \mathrm{Mn})$ of the synthesized polymers was determined using a gel permeation chromatography (GPC) consisting of a Waters 1515 isocratic HPLC pump, a Waters 2414 refractive index detector and three Waters columns (Styragel HT3, Styragel HT4, Styragel HT5). Freshly DMF with $50 \mathrm{mmol} / \mathrm{L}$ bistrifluoromethanesulfonimide lithium $\left(\operatorname{LiTf}_{2} \mathrm{~N}\right)$ salt served as the mobile phase and was delivered at a flow rate of $1.0 \mathrm{~mL} / \mathrm{min}$. Sample concentrations were ca. $8 \mathrm{mg}$ of polymer/mL of DMF, and the injection volume was $50 \mu \mathrm{L}$. At room temperature, X-Ray diffraction data was record on a Rigaku D/MAX-2500 diffractometer, using monochromatic $\mathrm{Cu} \mathrm{K}_{\alpha}$ radiation $(\lambda=1.5418 \AA$ ). While, X-Ray diffraction test at liquid nitrogen temperature was carried out on a GANESHA 300XL+ system, using monochromatic $\mathrm{Cu} \mathrm{K}$ radiation $(\lambda=1.5418 \AA)$. XRD spectrum was analyzed by using Jade 6 software, and XRD spectrum simulation was given by Materials Studio 8.0 software. Thermal gravity analysis (TGA) was performed on TA-Q800 and the heating rate was $10{ }^{\circ} \mathrm{C} / \mathrm{min}$. The differential scanning calorimetry (DSC) measurement was performed on TA-Q2000. The heating rate of DSC was $10{ }^{\circ} \mathrm{C} / \mathrm{min}$ and the data adopted came from the second temperature-rise period. Both TGA and DSC measurements were conducted under nitrogen atmosphere. Polarizing optical microscope (POM) observations 
were carried out via Nikon ECLIPSE LV100N POL and the heating rate was $1{ }^{\circ} \mathrm{C} / \mathrm{min}$ when observing. Magnetic properties measurements were performed using a Quantum Design VSM magnetometer utilizing a superconducting quantum interference device (SQUID) method. The samples of MIL and PMIL were measured after putting them in a Teflon capsule directly. DC magnetic susceptibility measurements were performed under applied magnetic fields from $10 \mathrm{kOe}$ while heating from $3 \mathrm{~K}$ to $300 \mathrm{~K}$, after cooling either in the presence (field cooling, FC) or the absence (zero field cooling, ZFC) of applied field. Magnetization (M) as a function of magnetic field $(\mathrm{H})$ was also measured in the $-10 \leq \mathrm{H}(\mathrm{kOe}) \leq 10$ range at several temperatures from $3 \mathrm{~K}$ to $380 \mathrm{~K}$.

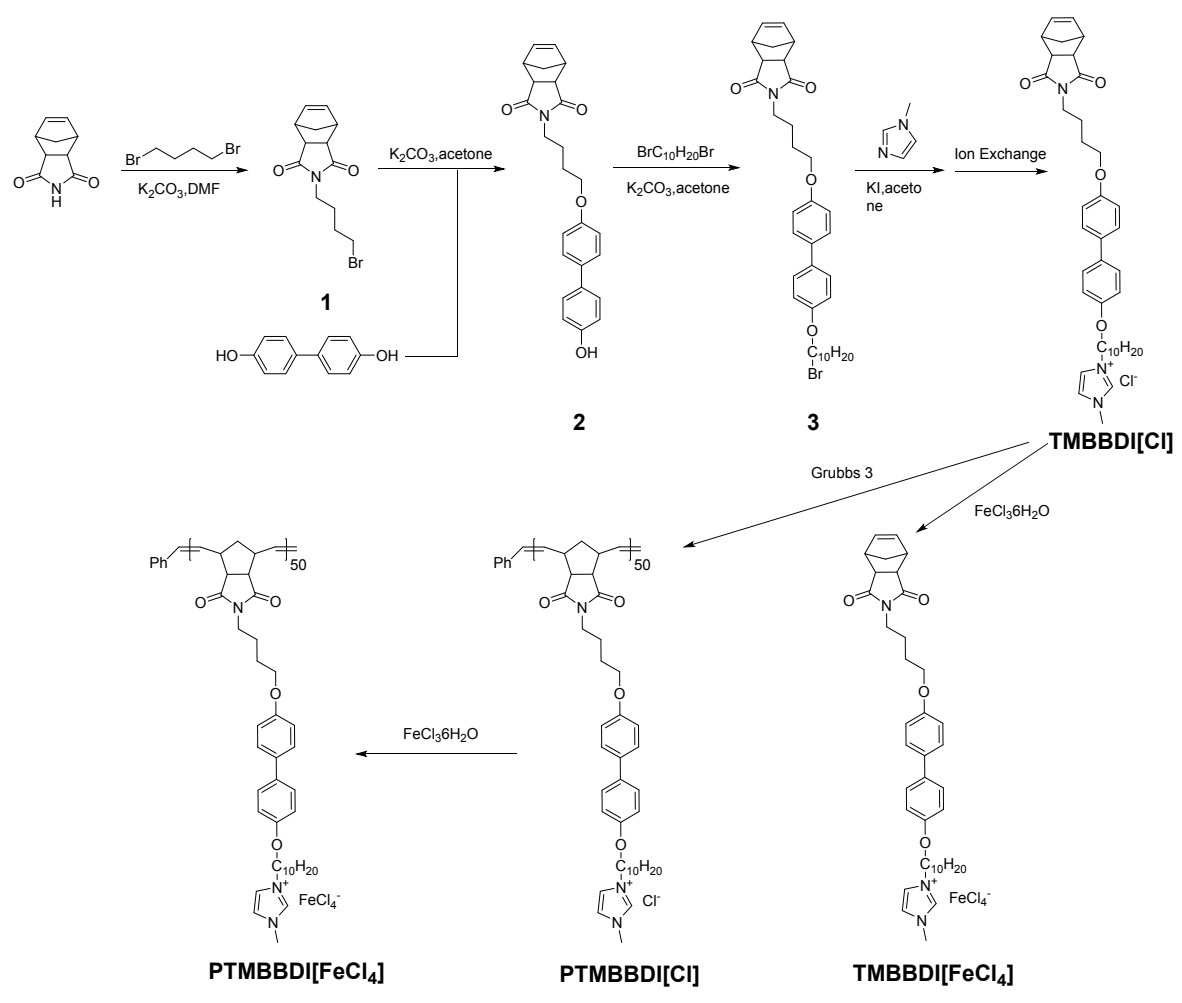

Scheme S1. Synthetic routes for TMBBDI[ $\left.\mathrm{FeCl}_{4}\right]$ and PTMBBDI[FeCl 4 . 
Table S1. The abbreviations and system nomenclatures of all compounds.

\begin{tabular}{|c|c|}
\hline Abbreviation & System nomenclature \\
\hline Compound 1 & 2-(4-bromobutyl)-3a,4,7,7a-tetrahydro-1H-4,7-methanoisoindole-1,3(2H)-dione \\
\hline Compound 2 & $\begin{array}{c}\text { 2-(4-((4'-hydroxy-[1,1'-biphenyl]-4-yl)oxy)butyl)-3a,4,7,7a-tetrahydro-1H-4,7-methanoi } \\
\text { soindole-1,3(2H)-dione }\end{array}$ \\
\hline Compound 3 & $\begin{array}{l}\text { 2-(4-((4'-((10-bromodecyl)oxy)-[1,1'-biphenyl]-4-yl)oxy)butyl)-3a,4,7,7a-tetrahydro-1H } \\
\text {-4,7-methanoisoindole-1,3(2H)-dione }\end{array}$ \\
\hline TMBBDI[Cl] & $\begin{array}{l}\text { 3-(10-((4'-(4-(1,3-dioxo-1,3,3a,4,7,7a-hexahydro-2H-4,7-methanoisoindol-2-yl)butoxy) } \\
\text {-[1,1'-biphenyl]-4-yl)oxy)decyl)-1-methyl-1H-imidazol-3-ium chloride }\end{array}$ \\
\hline TMBBDI[FeCl 4 & $\begin{array}{l}\text { 3-(10-((4'-(4-(1,3-dioxo-1,3,3a,4,7,7a-hexahydro-2H-4,7-methanoisoindol-2-yl)butoxy) } \\
\text {-[1,1'-biphenyl]-4-yl)oxy)decyl)-1-methyl-1H-imidazol-3-ium iron(III) chloride }\end{array}$ \\
\hline BTM & 2-(10-bromodecyl)-3a,4,7,7a-tetrahydro-1H-4,7-methanoisoindole-1,3(2H)-dione \\
\hline $\mathrm{HMI}[\mathrm{Cl}]$ & $\begin{array}{l}\text { 3-(10-(1,3-dioxo-1,3,3a,4,7,7a-hexahydro-2H-4,7-methanoisoindol-2-yl)decyl)-1-methy } \\
\text { 1-1H-imidazol-3-ium chloride }\end{array}$ \\
\hline $\mathrm{HMI}\left[\mathrm{FeCl}_{4}\right]$ & $\begin{array}{c}\text { 3-(10-(1,3-dioxo-1,3,3a,4,7,7a-hexahydro-2H-4,7-methanoisoindol-2-yl)decyl)-1-methy } \\
\text { 1-1H-imidazol-3-ium iron(III) chloride }\end{array}$ \\
\hline
\end{tabular}




\section{Synthesis of the MILs and PMILs}

\subsection{Synthesis of compound 1}

1,4-Dibromobutane $(13.2190 \mathrm{~g}, 60 \mathrm{mmol})$ and potassium carbonate $(6.9803 \mathrm{~g}, 50 \mathrm{mmol})$ were added to a $250 \mathrm{~mL}$ round-bottom flask. Then, 3a,4,7,7a-Tetrahydro-1H-4,7-methanoisoindole-1,3(2H)-dione (1.6651 g, $10 \mathrm{mmol})$ was dissolved in $100 \mathrm{~mL}$ DMF, and added to the flask dropwisely. The reaction was stirred for $24 \mathrm{~h}$ at room temperature. The resulting mixture was filtrated and the filtrate was evaporated under reduced pressure to remove the solvent. The residue was dissolved in dichloromethane $(100 \mathrm{~mL})$ and extracted with water $(50 \mathrm{~mL} \times 3)$. The organic layer was collected and dried over $\mathrm{MgSO}_{4}$. Then the solvent was removed via rotary evaporation. The crude product was purified with column chromatography (silica gel, petroleum ether/ethyl acetate 6/1) to give the compound 1 as a white needle-like powder. (Yield $74 \%)$

${ }^{1} \mathrm{H}$ NMR $\left(500 \mathrm{MHz}, \mathrm{CDCl}_{3}\right) \delta(\mathrm{ppm}) 6.12$ (t, $\left.J=1.8 \mathrm{~Hz}, 2 \mathrm{H}\right), 3.38$ (ddd, $J=14.1,7.0$, $4.8 \mathrm{~Hz}, 6 \mathrm{H}), 3.29-3.22(\mathrm{~m}, 2 \mathrm{H}), 1.84-1.71(\mathrm{~m}, 3 \mathrm{H}), 1.66-1.51(\mathrm{~m}, 3 \mathrm{H})$;

${ }^{13} \mathrm{C} \mathrm{NMR}\left(126 \mathrm{MHz}, \mathrm{CDCl}_{3}\right) \delta(\mathrm{ppm}) 177.61,134.50,52.26,45.73,44.89,37.29,32.72$, $29.88,26.42$.

\subsection{Synthesis of compound 2}

4,4'-Biphenol (4.7023 g, $25 \mathrm{mmol})$, potassium carbonate (6.9803 g, $50 \mathrm{mmol})$, potassium 
iodide $(83.0 \mathrm{mg}, 0.5 \mathrm{mmol})$ and catalytic amounts of 18 -crown- 6 were dissolved in 30 $\mathrm{mL}$ of acetone. Then, the mixture had refluxed for 30 minutes. Compound 1 (1.4909 g, 5 mmol) was dissolved in $30 \mathrm{~mL}$ acetone, and added to the mixture dropwise. The reaction was refluxed for $24 \mathrm{~h}$. The resulting mixture was transferred into $100 \mathrm{~mL}$ of water and acidified with $35 \% \mathrm{HCl}$ aqueous solution until $\mathrm{pH}=5-6$. Then, the mixture was extracted with ethyl acetate $(50 \mathrm{~mL} \times 3)$. The organic layer was collected and dried over $\mathrm{MgSO}_{4}$, and the solvents were removed via rotary evaporation. The crude product was purified by column chromatography (silica gel, petroleum ether/ethyl acetate 2/1) to give compound 2 as a white powder. (Yield 50\%)

${ }^{1} \mathrm{H}$ NMR $\left(500 \mathrm{MHz}, \mathrm{CDCl}_{3}\right) \delta(\mathrm{ppm}) 7.42(\mathrm{ddd}, J=9.5,5.8,2.4 \mathrm{~Hz}, 4 \mathrm{H}), 6.95-6.85(\mathrm{~m}$, 4H), $6.11(\mathrm{t}, J=1.7 \mathrm{~Hz}, 2 \mathrm{H}), 3.97(\mathrm{t}, J=6.1 \mathrm{~Hz}, 2 \mathrm{H}), 3.43(\mathrm{t}, J=7.2 \mathrm{~Hz}, 2 \mathrm{H}), 3.40(\mathrm{~m}$, $2 \mathrm{H}), 3.26(\mathrm{dd}, J=2.8,1.5 \mathrm{~Hz}, 2 \mathrm{H}), 1.79-1.71(\mathrm{~m}, 3 \mathrm{H}), 1.70-1.62(\mathrm{~m}, 2 \mathrm{H}), 1.55(\mathrm{~d}, J=8.8$ $\mathrm{Hz}, 1 \mathrm{H})$;

${ }^{13} \mathrm{C}$ NMR $\left(126 \mathrm{MHz}, \mathrm{CDCl}_{3}\right) \delta(\mathrm{ppm}) 178.18,157.95,155.06,134.49,133.50,133.27$, $127.86,127.62,115.56,114.78,67.21,52.30,45.81,44.95,38.16,26.67,24.59$.

\subsection{Synthesis of compound 3}

Compound 2 (403.5 mg, $1 \mathrm{mmol}), 1,10$-dibromodecane $(6.0622 \mathrm{~g}, 20 \mathrm{mmol})$ and potassium carbonate $(150.0 \mathrm{mg}, 1 \mathrm{mmol})$ were dissolved in $20 \mathrm{~mL}$ of acetone at a 100 $\mathrm{mL}$ round-bottom flask, which equipped with a spherical condenser. Then, the mixture was refluxed for $24 \mathrm{~h}$. After reaction, the resulting mixture was transferred into ethyl acetate $(50 \mathrm{~mL})$ and extracted with water $(50 \mathrm{~mL} \times 3)$. The organic layer was collected and 
dried over $\mathrm{MgSO}_{4}$, and the solvents were removed via rotary evaporation. The crude product was purified by column chromatography (silica gel, petroleum ether and petroleum ether/ethyl acetate 2/1) to give the compound 3 as a white powder. (Yield $85 \%)$

${ }^{1} \mathrm{H} \mathrm{NMR}\left(500 \mathrm{MHz}, \mathrm{CDCl}_{3}\right) \delta(\mathrm{ppm}) 7.45(\mathrm{~d}, J=8.6 \mathrm{~Hz}, 4 \mathrm{H}), 6.93(\mathrm{t}, J=9.2 \mathrm{~Hz}, 4 \mathrm{H})$, $6.11(\mathrm{~s}, 2 \mathrm{H}), 3.98(\mathrm{q}, J=6.2 \mathrm{~Hz}, 4 \mathrm{H}), 3.46-3.36(\mathrm{~m}, 6 \mathrm{H}), 3.28-3.22(\mathrm{~m}, 2 \mathrm{H}), 1.89-1.83$ (m, 2H), 1.79 (dd, $J=14.7,6.9 \mathrm{~Hz}, 2 \mathrm{H}), 1.76-1.71(\mathrm{~m}, 3 \mathrm{H}), 1.69-1.61(\mathrm{~m}, 2 \mathrm{H}), 1.54$ (d, $J$ $=8.7 \mathrm{~Hz}, 1 \mathrm{H}), 1.46(\mathrm{ddd}, J=18.4,10.8,4.9 \mathrm{~Hz}, 4 \mathrm{H}), 1.34(\mathrm{~d}, J=21.3 \mathrm{~Hz}, 6 \mathrm{H})$.

${ }^{13} \mathrm{C}$ NMR (126 MHz, $\left.\mathrm{CDCl}_{3}\right) \delta(\mathrm{ppm}) 177.87,158.39,158.13,134.62,133.66,133.45$, $127.81,114.91,114.90,68.21,67.36,52.41,45.91,45.08,38.21,34.18,32.98,29.60$, $29.51,29.49,29.46,28.90,28.32,26.87,26.20,24.76$.

HRMS (ESI) calculated for $\mathrm{C}_{35} \mathrm{H}_{44} \mathrm{NO}_{4} \mathrm{Br}$ (for $\left[\mathrm{M}^{+}+\mathrm{Na}\right]$, based on $100 \%$ abundance of $\left.{ }^{79} \mathrm{Br}\right), 644.2351$; found, 644.2345

\subsection{Synthesis of TMBBDI[Cl]}

Compound $3(155.7 \mathrm{mg}, 0.25 \mathrm{mmol})$ and catalytic amounts of potassium iodide were dissolved in $20 \mathrm{~mL}$ of acetone in a $50 \mathrm{~mL}$ round-bottom flask. Then $\mathrm{N}$-methyl imidazole ( $250 \mu \mathrm{L}, 3.10 \mathrm{mmol}$ ) was added to the solution. The mixture was refluxed for $48 \mathrm{~h}$. After reaction, the product was concentrated by rotary evaporation before processing. The concentrated solution was precipitated with excess diethyl ether for three times. After washing with a small amount of water and diethyl ether, a white solid product was given. (Yield 100\%) 
The solid obtained above (TMBBDI[I]) was dissolved in DMF/water (3:2 v/v). $5 \mathrm{~g}$ ionic exchange resin (IRA-400Cl) was put into the solution (the resin was washed by DMF and water mixed solution until the washing-solution became colorless) and stirred at room temperature for $12 \mathrm{~h}$. After reaction, the product was concentrated through reduced pressure distillation. The concentrated solution was precipitated with excess diethyl ether for three times. After vacuum drying, TMBBDI[Cl] (3-(10-((4'-(4-(1,3-dioxo-3a,4,7,7a-tetrahydro-1H-4,7-methanoisoindol-2(3H)-yl)butoxy) -[1,1'-biphenyl]-4-yl)oxy)decyl)-1-methyl-1H-imidazol-3-ium chloride) was given as a white solid. (Yield 100\%)

${ }^{1} \mathrm{H}$ NMR (500 MHz, DMSO- $\left.d_{6}\right) \delta(\mathrm{ppm}) 9.29(\mathrm{~s}, 1 \mathrm{H}), 7.80(\mathrm{~s}, 1 \mathrm{H}), 7.73(\mathrm{~s}, 1 \mathrm{H}), 7.49$ (d, $J=8.7 \mathrm{~Hz}, 4 \mathrm{H}), 6.94(\mathrm{dd}, J=8.7,1.9 \mathrm{~Hz}, 4 \mathrm{H}), 6.02(\mathrm{~s}, 2 \mathrm{H}), 4.15(\mathrm{t}, J=7.2 \mathrm{~Hz}, 2 \mathrm{H}), 3.95$ (q, $J=6.1 \mathrm{~Hz}, 6 \mathrm{H}), 3.84(\mathrm{~s}, 3 \mathrm{H}), 3.31(\mathrm{~s}, 2 \mathrm{H}), 3.25(\mathrm{t}, J=7.0 \mathrm{~Hz}, 2 \mathrm{H}), 3.22(\mathrm{~s}, 2 \mathrm{H}), 1.77$ (m, 2H), 1.72-1.66 (m, 2H), $1.60(\mathrm{~m}, 2 \mathrm{H}), 1.55-1.45(\mathrm{~m}, 4 \mathrm{H}), 1.39(\mathrm{~m}, 2 \mathrm{H}), 1.26(\mathrm{~m}$, $10 \mathrm{H})$.

${ }^{13} \mathrm{C}$ NMR $\delta(\mathrm{ppm}):\left(126 \mathrm{MHz}, \mathrm{DMSO}-d_{6}\right) \delta 178.16,158.36,137.17,135.01,132.95$, $132.87,127.85,124.27,122.94,115.53,115.49,68.15,67.60,52.48,49.46,45.89,44.94$, $37.98,36.48,30.07,29.75,29.44,29.42,29.38,29.03,26.81,26.20,26.17,24.76$.

High resolution MALDI-TOF-MS calculated for $\left[\mathrm{C}_{39} \mathrm{H}_{50} \mathrm{~N}_{3} \mathrm{O}_{4}\right]^{+}$(based on $100 \%$ abundance of ${ }^{79} \mathrm{Br}$ ): 624.3801 , found: 624.4590 .

\subsection{Synthesis of TMBBDI[FeCl 4}

TMBBDI[Cl] $(33.0 \mathrm{mg}, 0.05 \mathrm{mmol})$ was dissolved in $6 \mathrm{~mL}$ methanol in a $25 \mathrm{~mL}$ S10 
round-bottom flask. Equal equivalence $\mathrm{FeCl}_{3} \cdot 6 \mathrm{H}_{2} \mathrm{O}(13.5 \mathrm{mg}, 0.05 \mathrm{mmol})$ was added into the solution and stirred at $45{ }^{\circ} \mathrm{C}$ for $24 \mathrm{~h}$. After reaction, the product was concentrated by rotary evaporation. The concentrated solution was precipitated with excess diethyl ether for three times. After vacuum drying, TMBBDI $\left[\mathrm{FeCl}_{4}\right]$ was given as a brown solid. (Yield 100\%)

\subsection{Synthesis of PTMBBDI[FeCl 4}

TMBBDI[Cl] (66.0 mg, $0.10 \mathrm{mmol})$ was dissolved in a mixed solvent containing $250 \mu \mathrm{L}$ DMF and $150 \mu \mathrm{L}$ deionized water under inert atmosphere. G3 catalyst $\left(1.5 \mathrm{mg}, 2.00 \times 10^{-3}\right.$ mmol) was dissolved in $50 \mu \mathrm{L}$ DMF. Then, the TMBBDI[Cl] was injected into the catalyst solution under an inert atmosphere. The polymerization was conducted for $5 \mathrm{~h}$ at room temperature. After reaction, ethyl vinyl ether (EVE) $0.5 \mathrm{~mL}$ was added into this system to terminate the reaction. The solution was precipitated with excess diethyl ether for three times. After vacuum drying, a brown solid product was given.

${ }^{1} \mathrm{H}$ NMR (500 MHz, CDCl3) $\delta(\mathrm{ppm}) 9.36$ (broad, 1H), 7.80 (broad, 1H), 7.74 (broad, 1H), 7.37 (broad, 4H), 6.86 (broad, 4H), 5.27-5.15 (broad, 2H), 4.13 (broad, 2H), 3.84 (broad, 7H), 3.30-2.99 (broad, 6H), 1.73 (broad, 4H), 1.68-1.42 (broad, 6H), 1.33 (broad, 2H), 1.21 (broad, 10H).

PTMBBDI[Cl] (33.0 mg) was dissolved in $6 \mathrm{~mL}$ methanol at a $25 \mathrm{~mL}$ round-bottom flask. Taking the repeat unit as reference, equal equivalence of $\mathrm{FeCl}_{3} \cdot 6 \mathrm{H}_{2} \mathrm{O}(13.5 \mathrm{mg}, 0.05$ mmol) was added into the solution and kept the reaction for $24 \mathrm{~h}$ at $60^{\circ} \mathrm{C}$. After reaction, the product was concentrated by rotary evaporation. The concentrated solution was 
precipitated with excess diethyl ether for three times. After vacuum drying, PTMBBDI[ $\left.\mathrm{FeCl}_{4}\right]$ was obtained as a brown solid product.
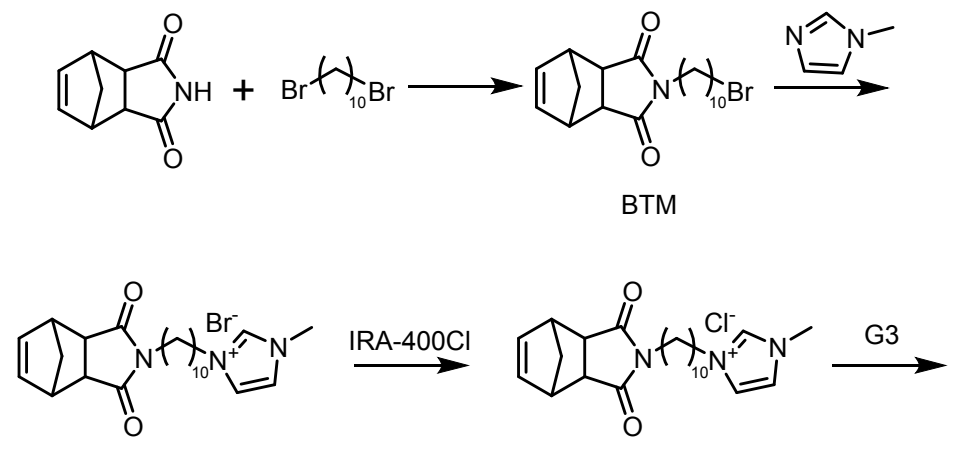

$\mathrm{HMI}[\mathrm{Br}] \quad \mathrm{HMI}[\mathrm{Cl}]$

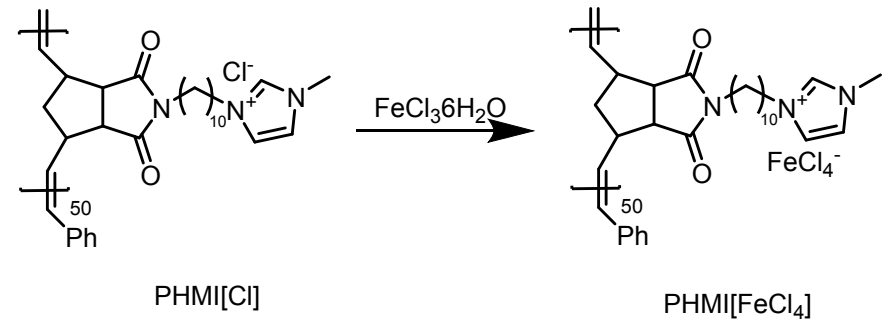

Scheme S2. Synthetic route for PHMI $\left[\mathrm{FeCl}_{4}\right]$.

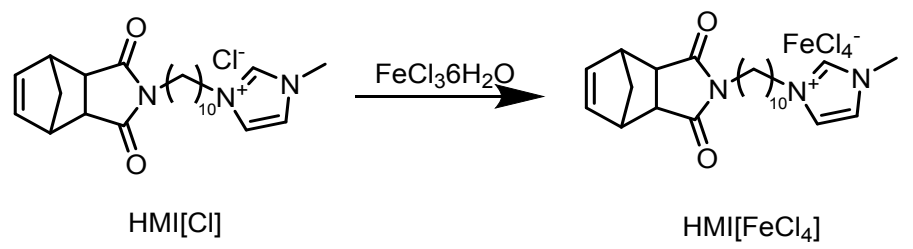

Scheme S3. Synthetic route for $\mathrm{HMI}\left[\mathrm{FeCl}_{4}\right]$.

\subsection{Synthesis of BTM}

1,10-Dibromodecane $(18.0500 \mathrm{~g}, 60 \mathrm{mmol})$ and potassium carbonate $(6.9803 \mathrm{~g}, 50 \mathrm{mmol})$ were added to a $250 \mathrm{~mL}$ round-bottom flask. Then, 3a,4,7,7a-tetrahydro-1H-4,7-methanoisoindole-1,3(2H)-dione (1.6651 g, $10 \mathrm{mmol})$ was 
dissolved in $100 \mathrm{~mL}$ DMF, and added to the flask dropwisely. The reaction was stirred for $24 \mathrm{~h}$ at $60^{\circ} \mathrm{C}$. The resulting mixture was filtrated and the filtrate was evaporated under reduced pressure to remove the solvent. The residue was dissolved in dichloromethane $(100 \mathrm{~mL})$ and extracted with water $(50 \mathrm{~mL} \times 3)$ was added to the solution. The organic layer was collected and dried over $\mathrm{MgSO}_{4}$, and the solvents were removed via rotary evaporation. The crude product was purified with column chromatography (silica gel, petroleum ether/ethyl acetate 5/1) to give the BTM as a colorless oil product. (Yield $82 \%)$

${ }^{1} \mathrm{H}$ NMR (400 MHz, $\left.\mathrm{CDCl}_{3}\right) \delta(\mathrm{ppm}) 6.10(\mathrm{~s}, 2 \mathrm{H}), 3.44-3.38(\mathrm{~m}, 4 \mathrm{H}), 3.35-3.30(\mathrm{~m}$, 2H), $3.25(\mathrm{~d}, J=1.4 \mathrm{~Hz}, 2 \mathrm{H}), 1.91-1.81(\mathrm{~m}, 2 \mathrm{H}), 1.74(\mathrm{~d}, J=8.7 \mathrm{~Hz}, 1 \mathrm{H}), 1.55(\mathrm{~d}, J=$ $8.7 \mathrm{~Hz}, 1 \mathrm{H}), 1.49-1.20(\mathrm{~m}, 14 \mathrm{H})$.

${ }^{13} \mathrm{C}$ NMR (101 MHz, $\left.\mathrm{CDCl}_{3}\right) \delta(\mathrm{ppm}) 177.75,134.39,52.20,45.70,44.88,38.40,34.03$, $32.80,29.32,29.29,29.04,28.67,28.12,27.76,26.82$.

\subsection{Synthesis of HMI[Cl]}

BTM (1.1470 g, $3 \mathrm{mmol}$ ) was dissolved in $20 \mathrm{~mL}$ of THF in a $50 \mathrm{~mL}$ round-bottom flask. Then N-methyl imidazole $(750 \mu \mathrm{L}, 9.30 \mathrm{mmol})$ was added to the solution. The mixture was refluxed for $48 \mathrm{~h}$. After reaction, the product was concentrated by rotary evaporation before processing. The concentrated solution was precipitated with excess diethyl ether for three times. Finally, a faint yellow oil product was given. (Yield 100\%)

The product obtained above was dissolved in methanol. $10 \mathrm{~g}$ ionic exchange resin (IRA-400Cl) was put into the solution (the resin was washed by methanol until it became 
colorless) and stirred at room temperature for $12 \mathrm{~h}$. After reaction, the product was concentrated through reduced pressure distillation. The concentrated solution was precipitated with excess diethyl ether for three times. After vacuum drying, white HMI [Cl] was given. (Yield 100\%)

${ }^{1} \mathrm{H}$ NMR (400 MHz, $\left.\mathrm{CDCl}_{3}\right) \delta(\mathrm{ppm}) 10.85$ (s, 1H), 7.29 (s, 1H), $7.22(\mathrm{~s}, 1 \mathrm{H}), 6.08$ (s, 2H), $4.31(\mathrm{t}, J=5.8 \mathrm{~Hz}, 2 \mathrm{H}), 4.13(\mathrm{~s}, 3 \mathrm{H}), 3.38(\mathrm{~s}, 2 \mathrm{H}), 3.30(\mathrm{t}, J=4.9 \mathrm{~Hz}, 2 \mathrm{H}), 3.24(\mathrm{~s}$, 2H), $1.73(\mathrm{~d}, J=7.0 \mathrm{~Hz}, 1 \mathrm{H}), 1.53(\mathrm{~d}, J=7.0 \mathrm{~Hz}, 1 \mathrm{H}), 1.44-1.16(\mathrm{~m}, 16 \mathrm{H})$.

${ }^{13} \mathrm{C}$ NMR (101 MHz, $\left.\mathrm{CDCl}_{3}\right) \delta(\mathrm{ppm})$ 177.81, 138.21, 134.39, 123.31, 121.56, 52.21, $50.12,45.71,44.87,38.36,36.66,30.26,29.19,29.15,28.92,28.86,27.69,26.74,26.17$.

\subsection{Synthesis of $\mathrm{HMI}\left[\mathrm{FeCl}_{4}\right]$}

$\mathrm{HMI}[\mathrm{Cl}](84.0 \mathrm{mg}, 0.2 \mathrm{mmol})$ was dissolved in $6 \mathrm{~mL}$ methanol in a $25 \mathrm{~mL}$ round-bottom flask. Equal equivalence $\mathrm{FeCl}_{3} \cdot 6 \mathrm{H}_{2} \mathrm{O}(54.0 \mathrm{mg}, 0.2 \mathrm{mmol})$ was added into the solution and stirred at $45{ }^{\circ} \mathrm{C}$ for $24 \mathrm{~h}$. After reaction, the product was concentrated by rotary evaporation. The concentrated solution was precipitated with excess diethyl ether for three times. After vacuum drying, $\mathrm{HMI}\left[\mathrm{FeCl}_{4}\right]$ was given as a brown ropy liquid. (Yield $100 \%)$

\subsection{Synthesis of $\mathrm{PHMI}\left[\mathrm{FeCl}_{4}\right]$}

HMI $[\mathrm{Cl}](84.0 \mathrm{mg}, 0.2 \mathrm{mmol})$ was dissolved in $200 \mu \mathrm{L}$ dichloromethane. G3 catalyst (2.9 $\mathrm{mg}, 4.00 \times 10^{-3} \mathrm{mmol}$ ) was dissolved in $100 \mu \mathrm{L}$ dichloromethane. Then, the $\mathrm{HMI}[\mathrm{Cl}]$ was injected into the catalyst solution. And, the polymerization was conducted for $0.5 \mathrm{~h}$ at room temperature. After reaction, ethyl vinyl ether (EVE) $0.5 \mathrm{~mL}$ was added into this 
system to terminate the reaction. The solution was precipitated with excess diethyl ether for three times. After vacuum drying, a brown solid product was given. The obtained PHMI[Cl] was dissolved in $15 \mathrm{~mL}$ methanol at a $50 \mathrm{~mL}$ round-bottom flask. Take the repeat unit as reference, equal equivalence of $\mathrm{FeCl}_{3} \cdot 6 \mathrm{H}_{2} \mathrm{O}(54.0 \mathrm{mg}, 0.2 \mathrm{mmol})$ was added into the solution and kept the reaction for $24 \mathrm{~h}$ at $60{ }^{\circ} \mathrm{C}$. After reaction, the product was concentrated by rotary evaporation. The concentrated solution was precipitated with excess diethyl ether for three times. After vacuum drying, $\mathrm{PHMI}\left[\mathrm{FeCl}_{4}\right]$ was obtained as a brown solid product. 


\section{NMR analyses of all the compounds}

\subsection{Preparation of magnetic monomer TMBBDI[FeCl 4$]$}

Briefly, compound 11 was $\quad 1$ prepared 3a,4,7,7a-Tetrahydro-1H-4,7-methanoisoindole-1,3(2H)-dione and 1,4-dibromobutane. To introduce a mesogenic unit, compound 1 and 4,4'-biphenol were reacted by a $\mathrm{S}_{\mathrm{N}} 2$ reaction. Then the compound 3 could also be obtained by a $\mathrm{S}_{\mathrm{N}} 2$ reaction from compound 2 and 1,10-dibromodecane. Through a quaternization with 1-methylimidazole under potassium iodide and the ion exchange reaction using chloride ion exchange resin, compound 3 could translate into TMBBDI[Cl]. This polymerizable monomer was characterized by NMR and the spectra were given below. Other intermediate products involved in the process of synthesis were unambiguously characterized by ${ }^{1} \mathrm{H}$ and ${ }^{13} \mathrm{C}$ NMR and the results were also given. The signals of all the protons and carbon nuclears were completely interpreted reasonably. The cation of TMBBDI $[\mathrm{Cl}]\left(\left[\mathrm{C}_{39} \mathrm{H}_{50} \mathrm{~N}_{3} \mathrm{O}_{4}\right]^{+}\right)$was also verified by MALDI-TOF-MS which showed a $\mathrm{m} / \mathrm{z}$ of 624.4590 , close to the calculated value 624.3801 .

\subsection{Preparation of magnetic polymer PTMBBDI[FeCl $\left.{ }_{4}\right]$}

In this paper, magnetic polymer $\mathrm{TMBBDI}\left[\mathrm{FeCl}_{4}\right]$ was prepared by the post-modification method of PTMBBDI[Cl] to avoid the catalyst poisoning via direct polymerization of 
TMBBDI $\left[\mathrm{FeCl}_{4}\right] .{ }^{3}$ From the ${ }^{1} \mathrm{H}$ NMR test result, all the signals showed typically broad peaks of polymer. Compared with the monomer TMBBDI[Cl], the signal at $6.03 \mathrm{ppm}$ which assigned to the double bond in the norbornene disappeared, and new broad peaks at the range of 5.21-5.60 ppm were assigned to the protons from the double bond in the polymer main chain. The degree of polymerization (DP) could be calculated from ${ }^{1} \mathrm{H}$ NMR by comparing the double bond signals in before and after the polymerization and the value was 50 .

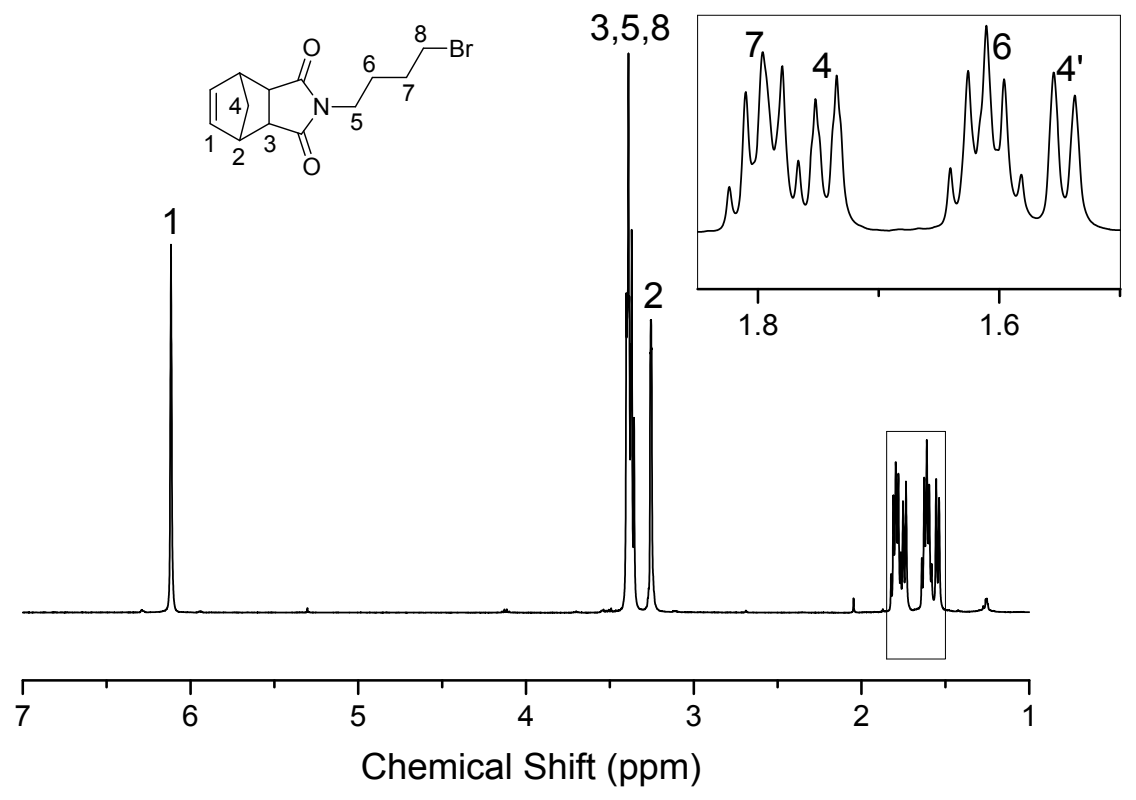

Figure S1. ${ }^{1} \mathrm{H}$ NMR of compound 1 in $\mathrm{CDCl}_{3}$. 


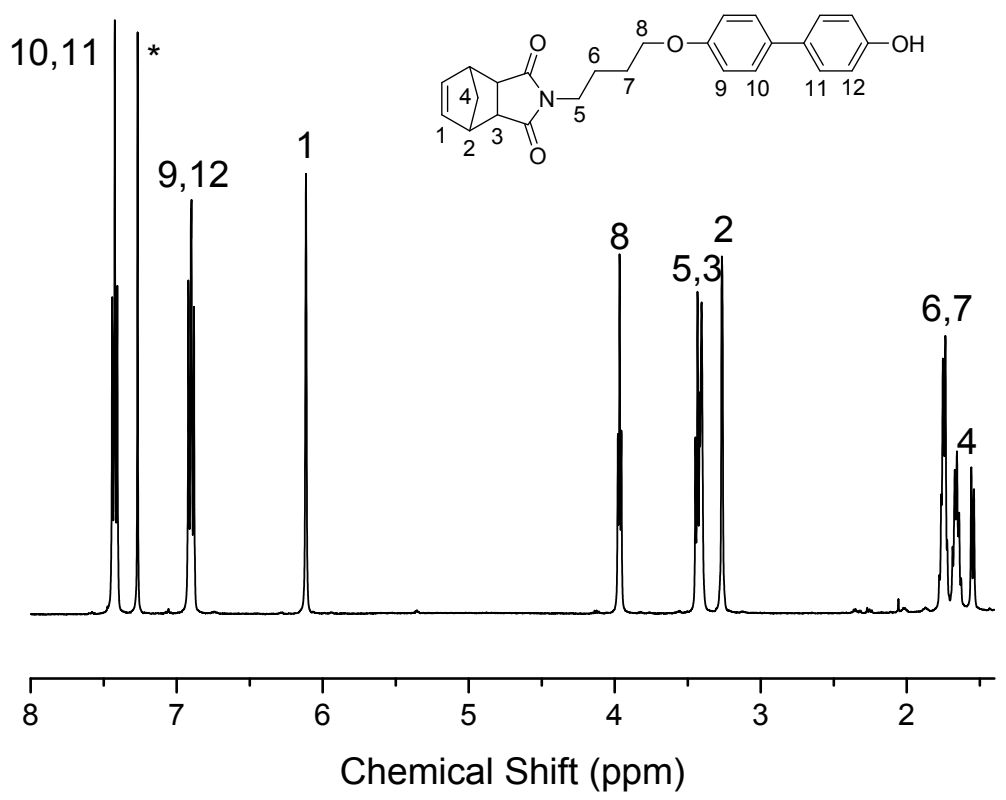

Figure S2. ${ }^{1} \mathrm{H}$ NMR of compound 2 in $\mathrm{CDCl}_{3}$.

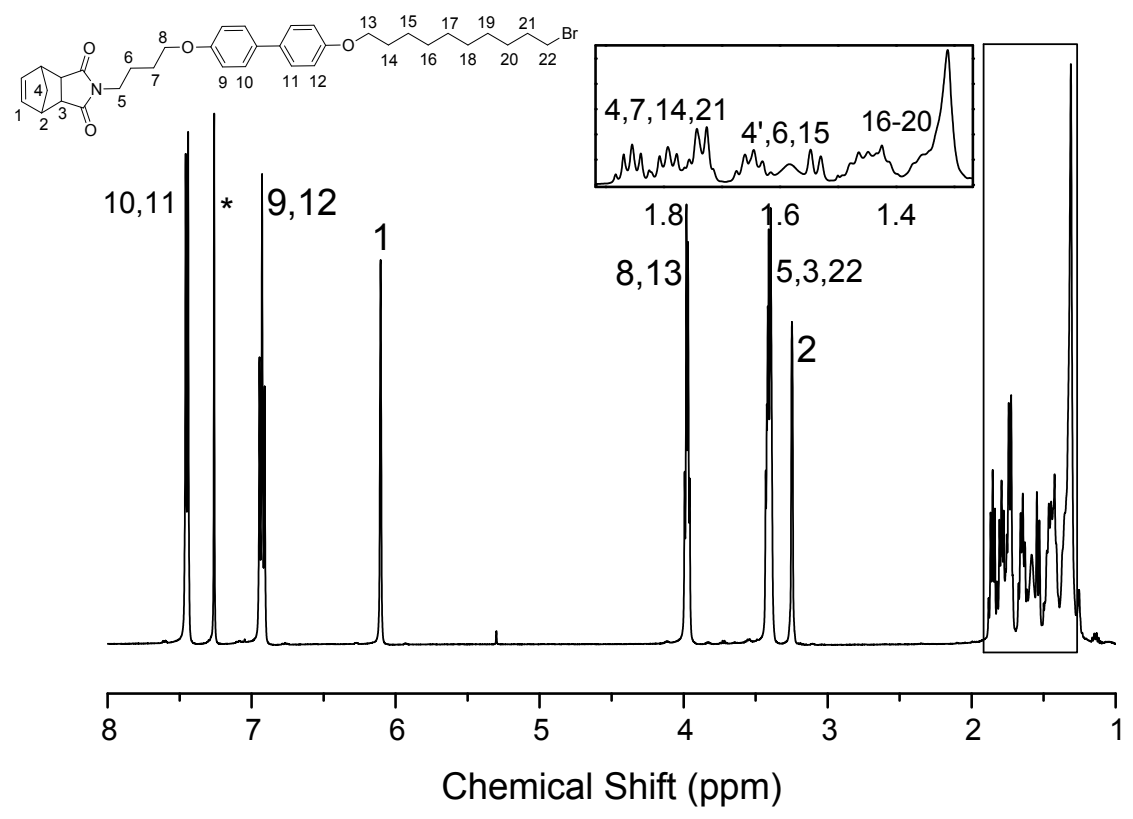

Figure S3. ${ }^{1} \mathrm{H}$ NMR of compound 3 in $\mathrm{CDCl}_{3}$. 


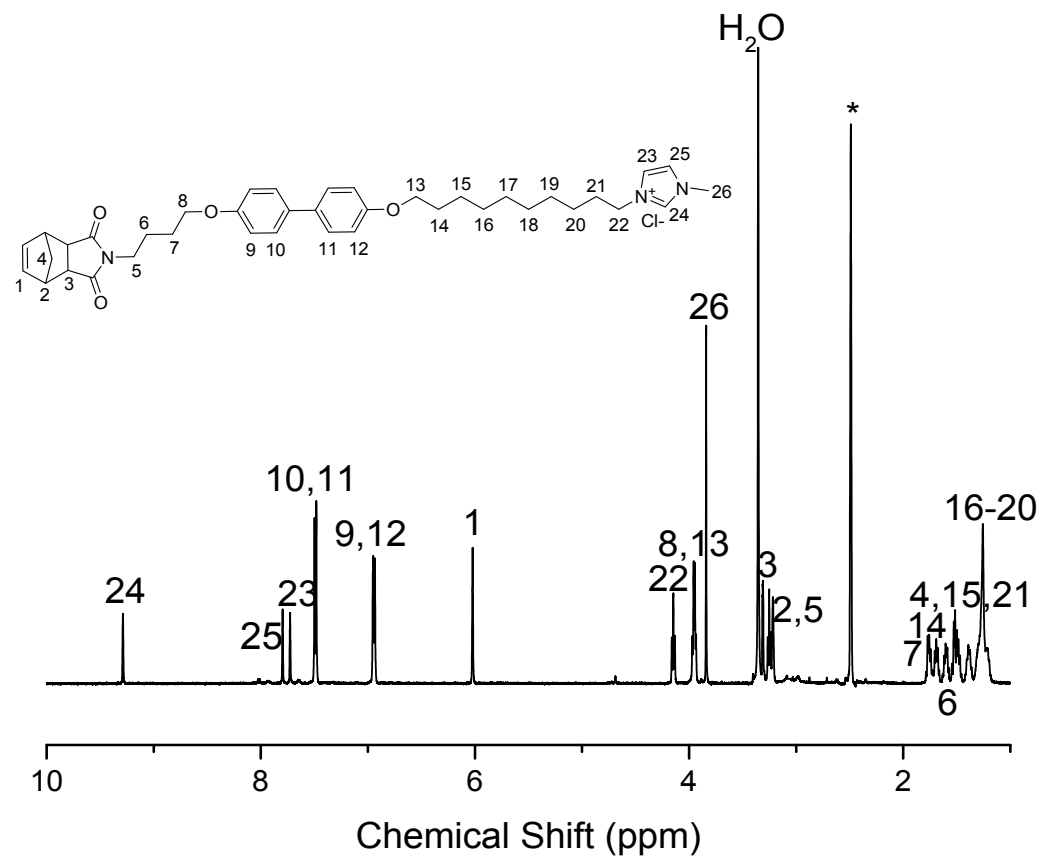

Figure S4. ${ }^{1} \mathrm{H}$ NMR of TMBBDI[Cl] in DMSO- $d_{6}$.

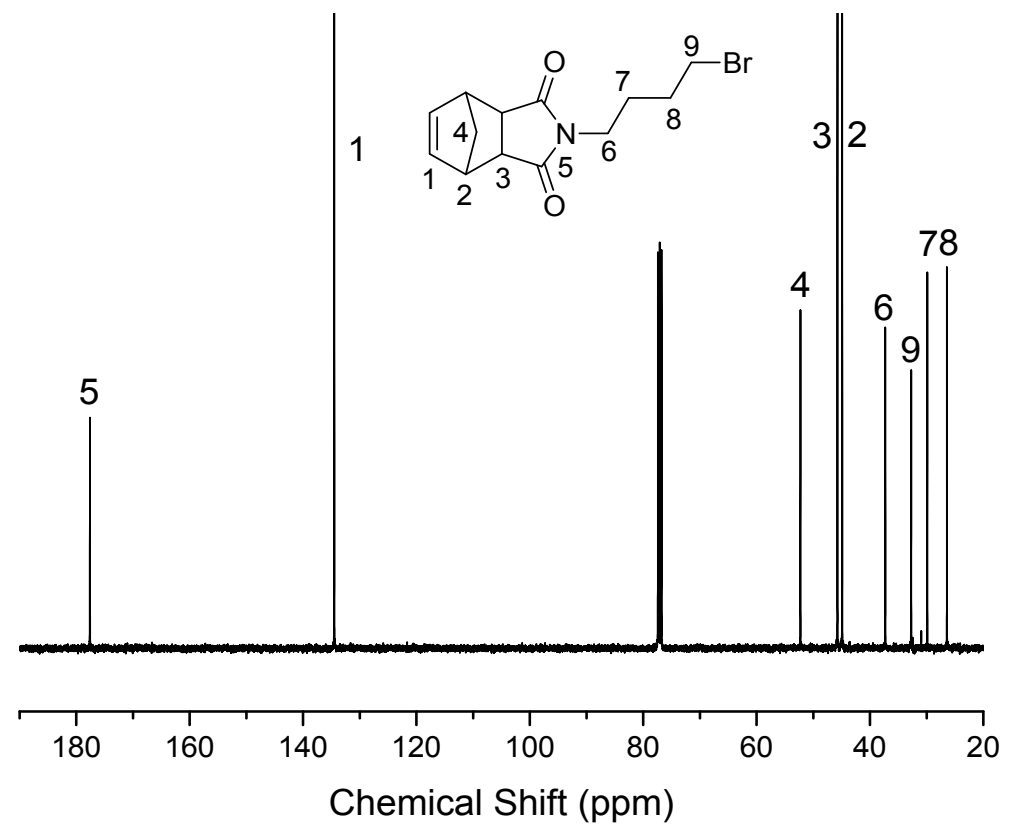

Figure S5. ${ }^{13} \mathrm{C}$ NMR of compound 1 in $\mathrm{CDCl}_{3}$. 


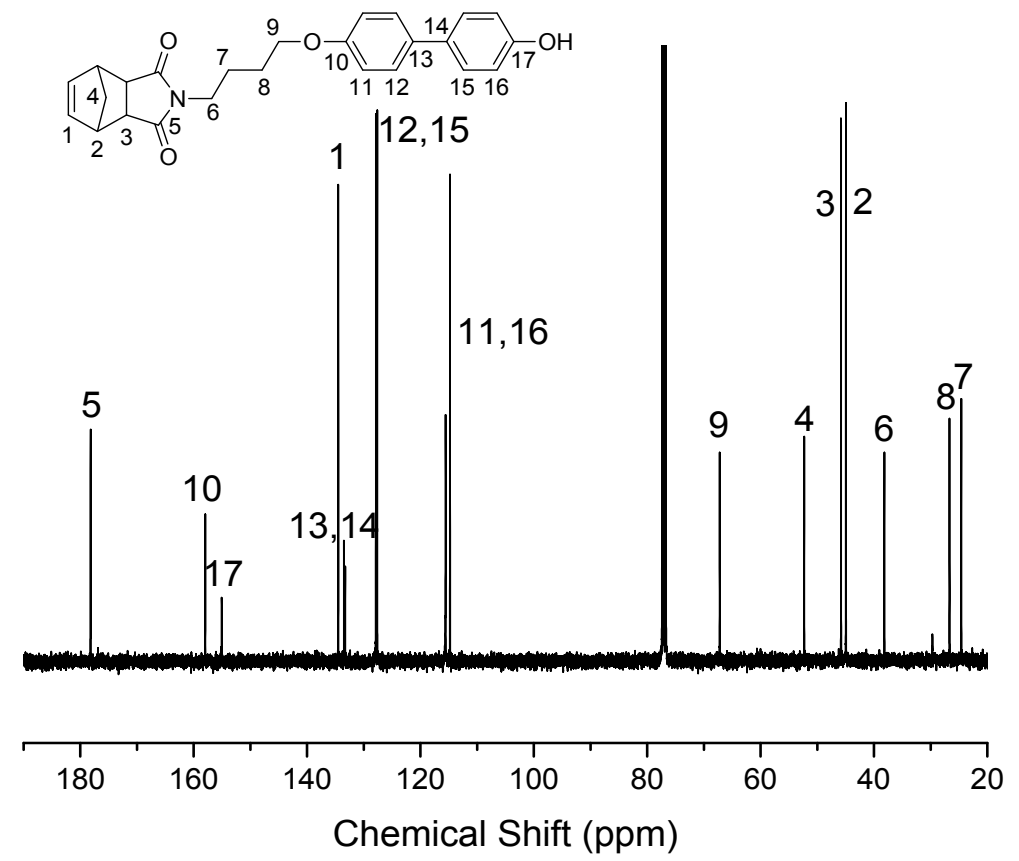

Figure S6. ${ }^{13} \mathrm{C}$ NMR of compound 2 in $\mathrm{CDCl}_{3}$.

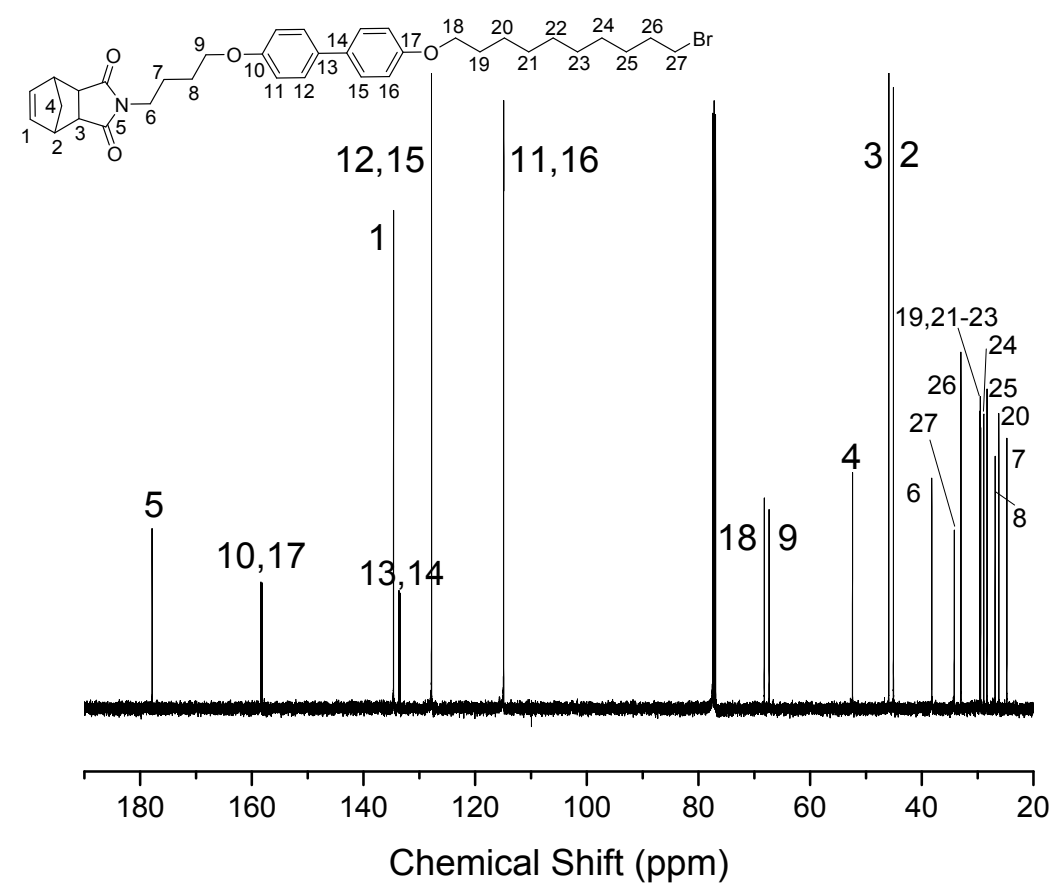

Figure S7. ${ }^{13} \mathrm{C}$ NMR of compound 3 in $\mathrm{CDCl}_{3}$. 


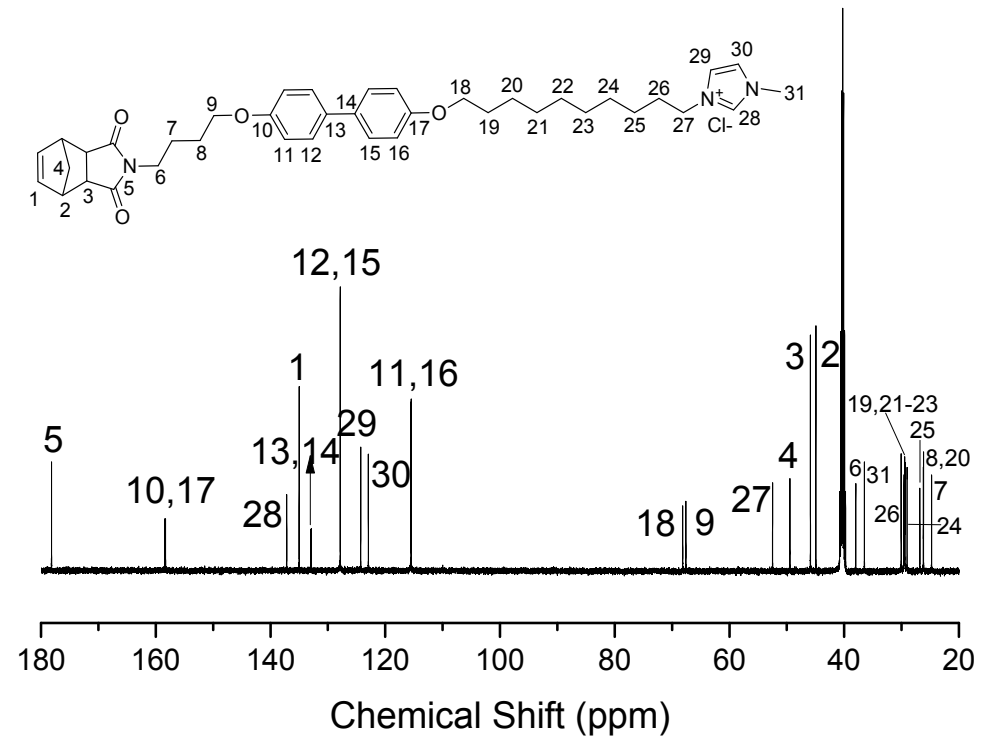

Figure S8. ${ }^{13} \mathrm{C}$ NMR of TMBBDI[Cl] in DMSO- $d_{6}$.

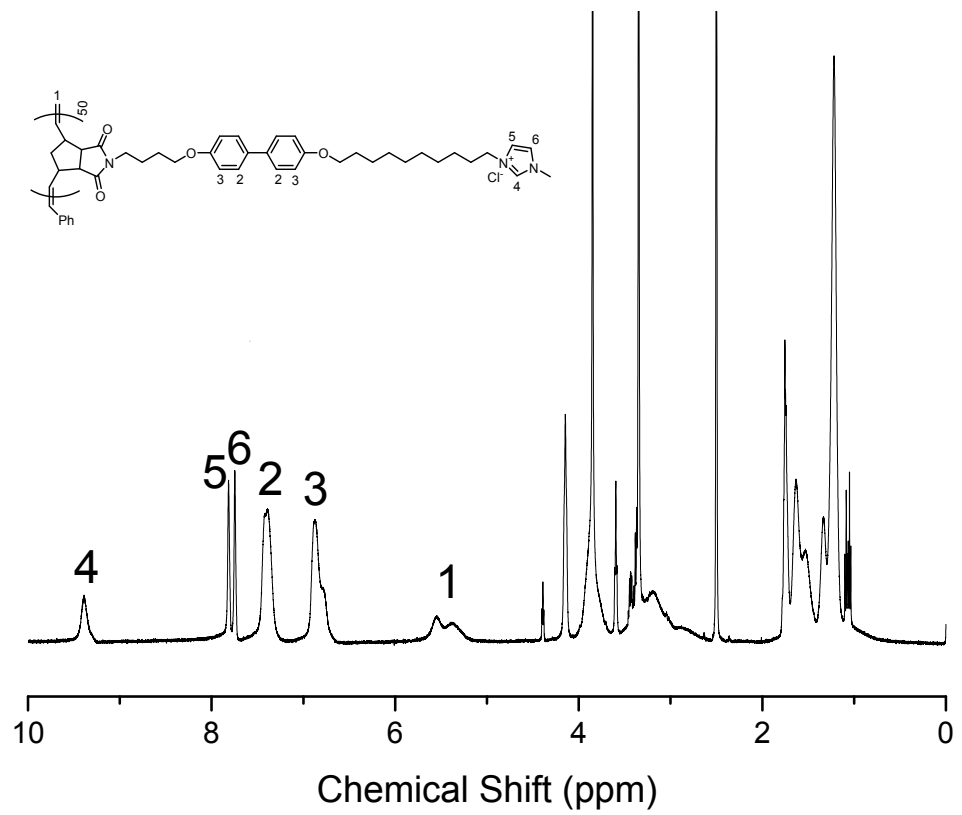

Figure S9. ${ }^{1} \mathrm{H}$ NMR of PTMBBDI[Cl] in DMSO- $d_{6}$. 


\subsection{Preparation of reference magnetic polymer $\mathrm{PHMI}\left[\mathrm{FeCl}_{4}\right]$}

PHMI $\left[\mathrm{FeCl}_{4}\right]$ was prepared as reference in this paper. Compared with magnetic polymer PTMBBDI $\left[\mathrm{FeCl}_{4}\right]$, the structure of PHMI $\left[\mathrm{FeCl}_{4}\right]$ didn't contain biphenyl units, which could insured that the physics behaviors cannot affect by the $\pi-\pi$ stacking interaction. From the ${ }^{1} \mathrm{H}$ NMR test result, the signals of intermediates and polymer were reasonably assigned. Compared with the PTMBBDI[Cl] (Figure S4), the signals of biphenyl units were disappeared. Also, the integration areas between 1 to $4 \mathrm{ppm}$ were decreased assigned to the space between norbornene and biphenyl removed. In order to exclude the impact of molecule weight, degree of polymerization was also controlled to 50 .
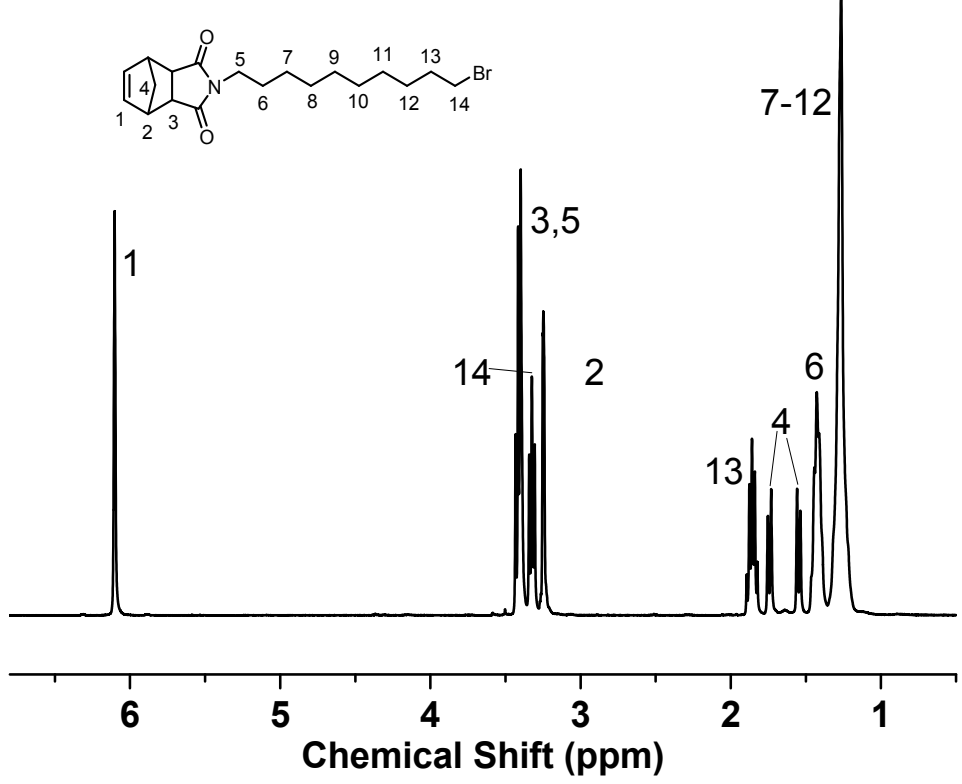

Figure S10. ${ }^{1} \mathrm{H}$ NMR of $\mathrm{BTM}$ in $\mathrm{CDCl}_{3}$. 


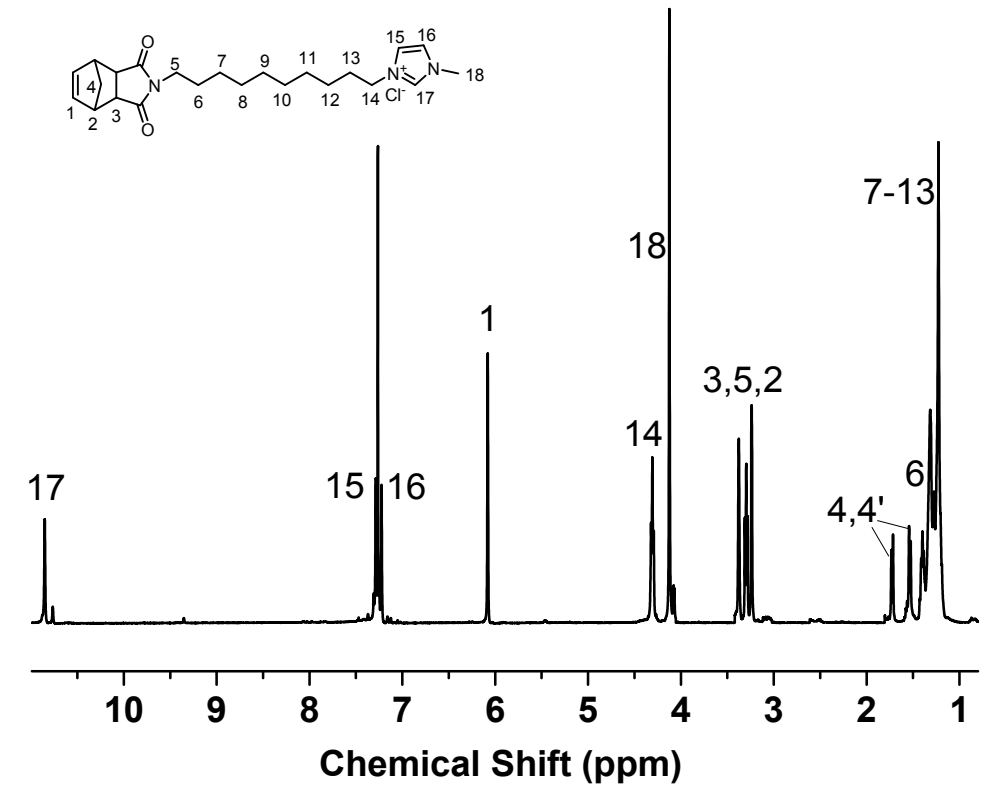

Figure S11. ${ }^{1} \mathrm{H}$ NMR of $\mathrm{HMI}[\mathrm{Cl}]$ in $\mathrm{CDCl}_{3}$.

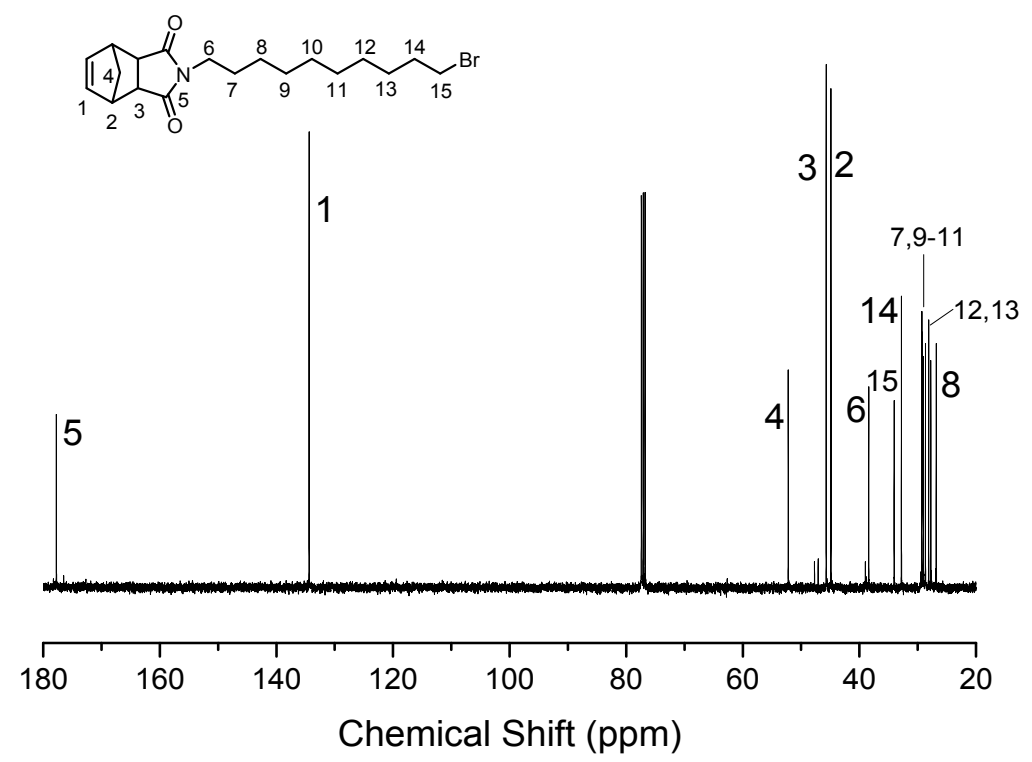

Figure S12. ${ }^{13} \mathrm{C}$ NMR of BTM in $\mathrm{CDCl}_{3}$. 


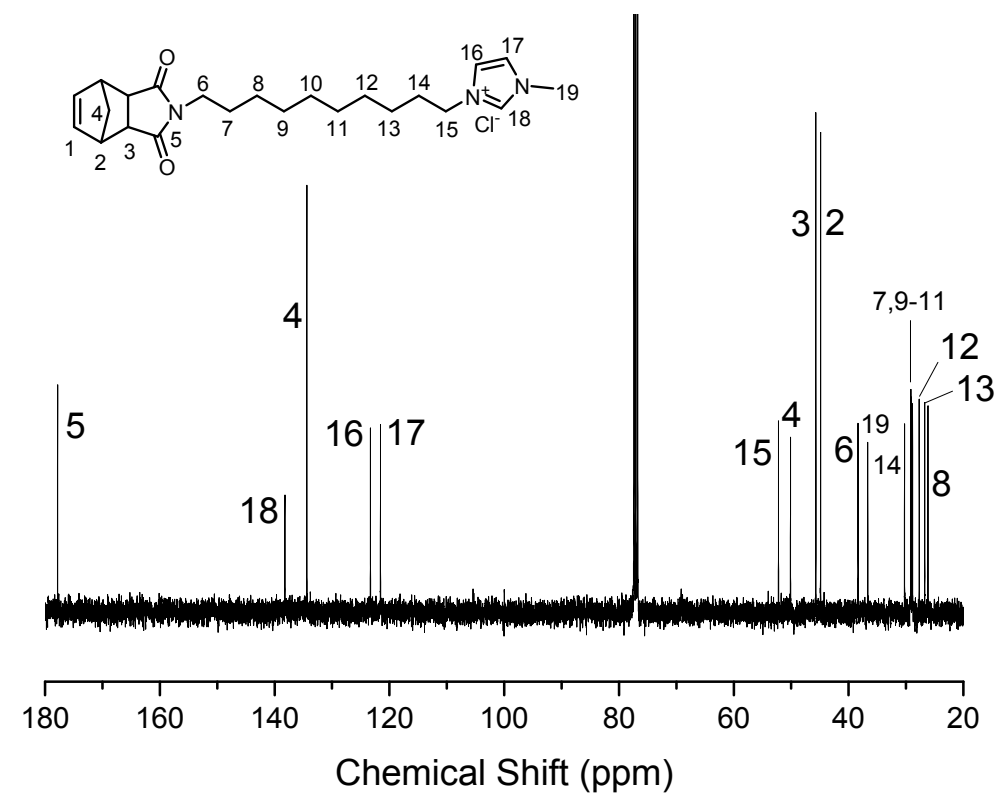

Figure S13. ${ }^{13} \mathrm{C}$ NMR of $\mathrm{HMI}[\mathrm{Cl}]$ in $\mathrm{CDCl}_{3}$.

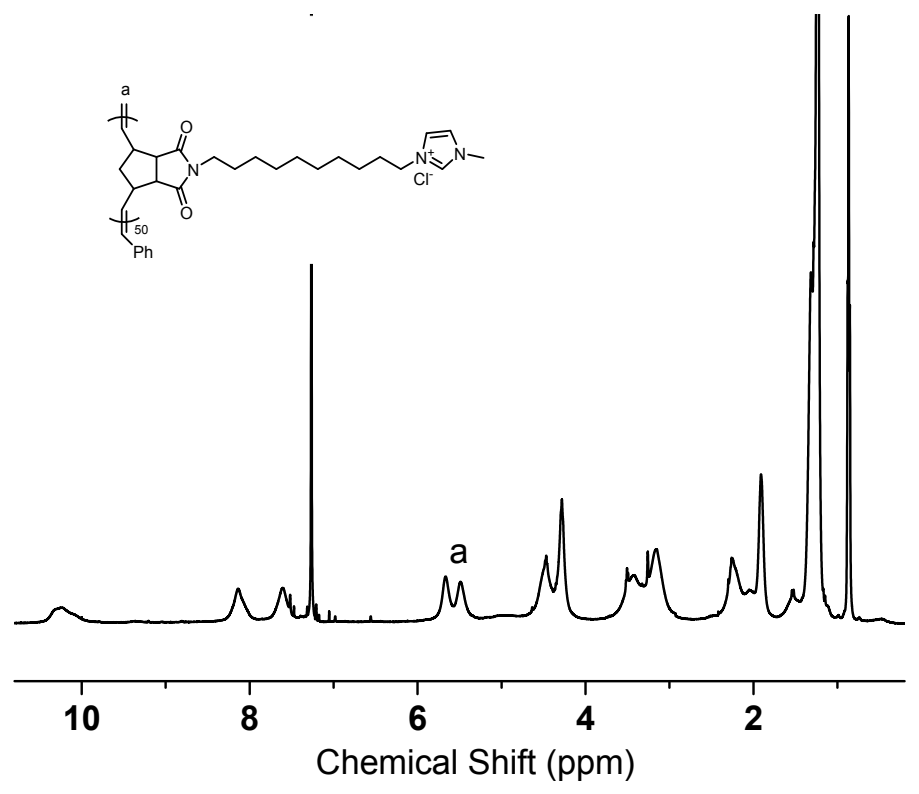

Figure S14. ${ }^{1} \mathrm{H}$ NMR of PHMI[Cl] in $\mathrm{CDCl}_{3}$. 


\section{Kinetics for TMBBDI[Cl] polymerization}

TMBBDI[Cl] (99.1 mg, $0.15 \mathrm{mmol})$ was dissolved in a mixed solvent containing $375 \mu \mathrm{L}$ DMF and $225 \mu \mathrm{L}$ deionized water under inert atmosphere. G3 catalyst $\left(2.2 \mathrm{mg}, 3.00 \times 10^{-3}\right.$ mmol) was dissolved in $50 \mu \mathrm{L}$ DMF. Then, the TMBBDI[Cl] was injected into the catalyst solution under an inert atmosphere. Samples were taken at different interval times and added to a vial containing $0.5 \mathrm{~mL}$ EVE to terminate the reaction. The solution was precipitated with excess diethyl ether for three times and the conversion rate was analyzed via ${ }^{1} \mathrm{H}$ NMR.

Kinetic studies were operated by taking samples at different intervals. As calculated from the area of double bond of both monomer and polymer, the conversion of TMBBDI[Cl] was obtained, and thus the DP at different intervals was calculated. As shown in Figuer $\mathrm{S} 15$, the DP of PTMBBDI[Cl] increased linearly with the extension of reaction time, which certified the living polymerization of TMBBDI[Cl] catalyzed by $\mathrm{G} 3$ catalyst.

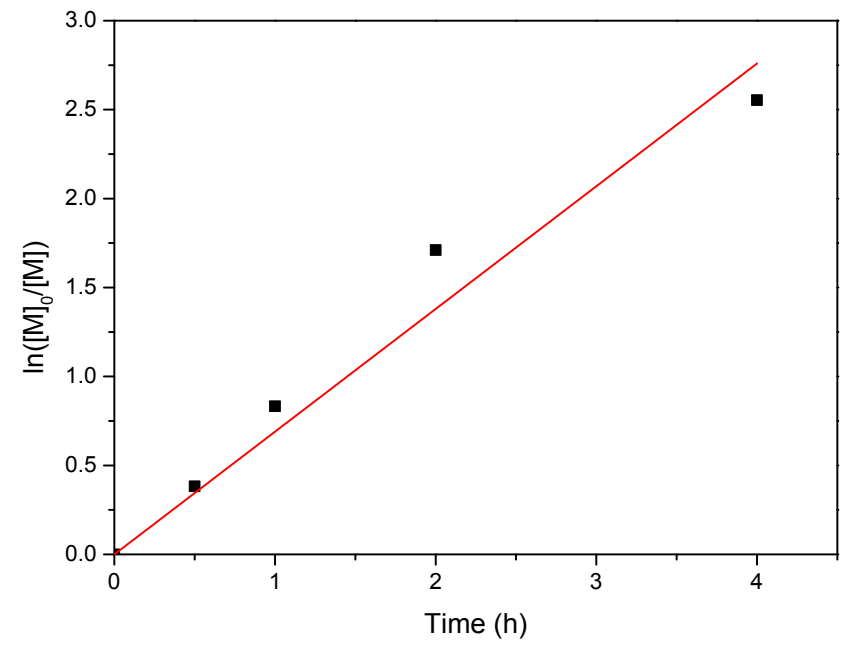

Figure S15. Polymerization kinetics of PTMBBDI[Cl]. 


\section{GPC of PTMBBDI[Cl]}

Gel Permeation Chromatography (GPC) characterization of the polyelectrolyte was also operated via the strategy reported by Matyjaszewski's group. ${ }^{4}$ As shown in Figure S16, the peak was mainly symmetric with a PDI was 1.26 and a molecular weight $\left(M_{n}\right)$ was $57.2 \mathrm{kDa}$.

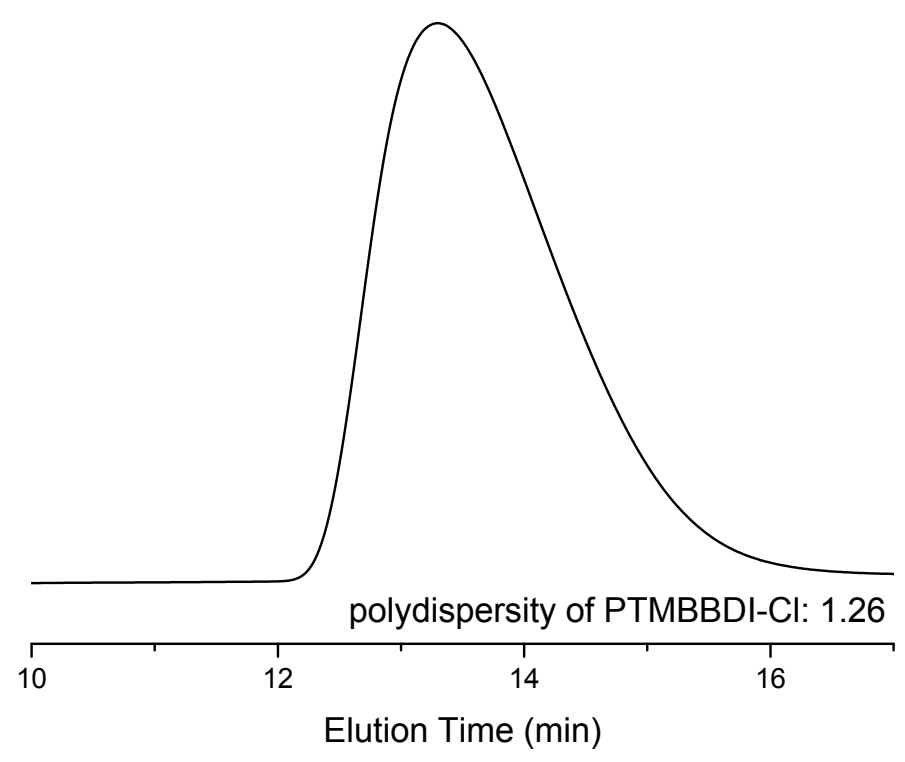

Figure S16. GPC trace of PTMBBDI[Cl]. 


\section{Mass spectra of compounds}

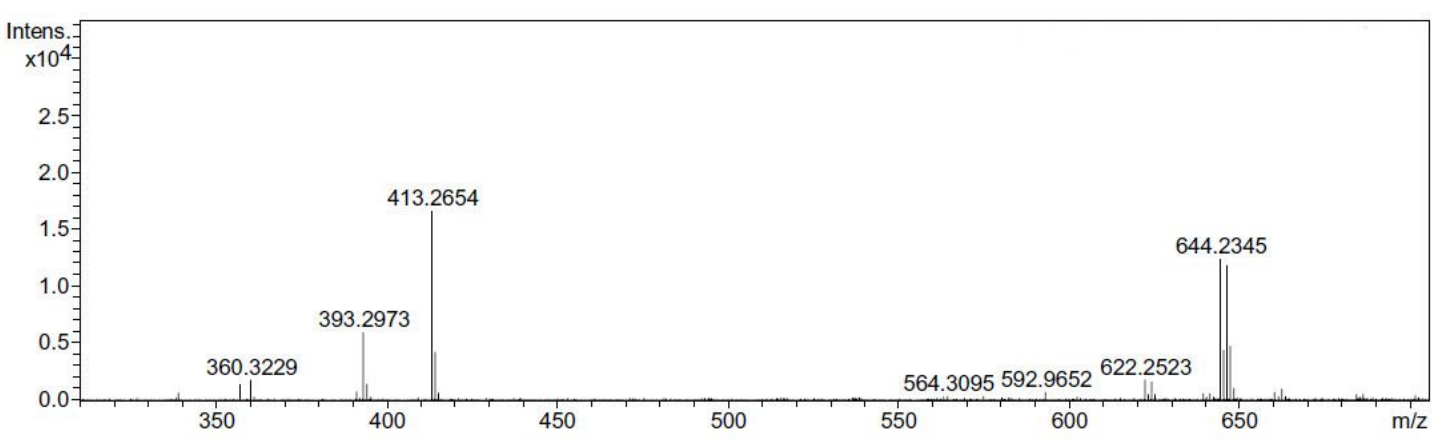

Figure S17. HRMS of [compound $3+\mathrm{Na}^{+}$] (Calcd m/z: 644.24, found m/z: 644.23).

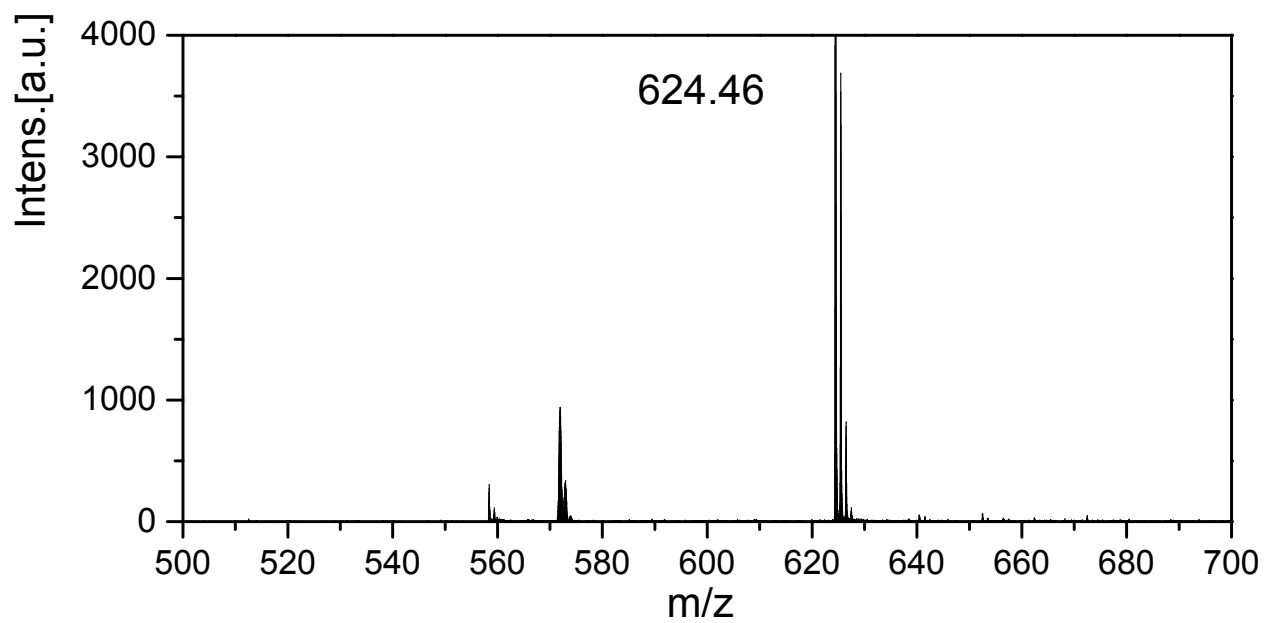

Figure S18. MALDI-TOF-MS of [TMBBDI] ${ }^{+}$with a HCCA matrix (Calcd m/z: 624.38, found m/z: 624.46). 


\section{Raman spectra}

Magnetic monomer and magnetic polymer were prepared by complexing $\mathrm{Cl}-$ containing poly(ionic liquid)s with $\mathrm{FeCl}_{3}$ and precipitated in diethyl ether until the solution was colorless for further purification. Magnetic anion $\mathrm{FeCl}_{4}^{-}$can be observed from Raman spectra as shown in Figure 1c. The $785 \mathrm{~nm}$ laser was used as the excitation source in order to avoid fluorescence from impurities. ${ }^{5}$ The sharp peaks appeared at $334 \mathrm{~cm}^{-1}$ in the spectra were assigned to the symmetric $\mathrm{Fe}-\mathrm{Cl}$ bond stretching vibrations of $\mathrm{FeCl}_{4}^{-}$. The peaks at $134 \mathrm{~cm}^{-1}$ in the spectrum were assigned to the $\mathrm{Fe}-\mathrm{Cl}$ bond bending vibrations. Thus, it can be confirmed that the tested samples contain $\mathrm{FeCl}_{4}{ }^{-}$anions. ${ }^{6}$

To exclude the presence of iron-based metal oxides, the Raman spectra of $\mathrm{Fe}_{2} \mathrm{O}_{3}$ and $\mathrm{Fe}_{3} \mathrm{O}_{4}$ were tested. Their characteristic peaks are located at 226, 295, 409 and $497 \mathrm{~cm}^{-1}$ for $\mathrm{Fe}_{2} \mathrm{O}_{3}$ and $696 \mathrm{~cm}^{-1}$ for $\mathrm{Fe}_{3} \mathrm{O}_{4}$. 

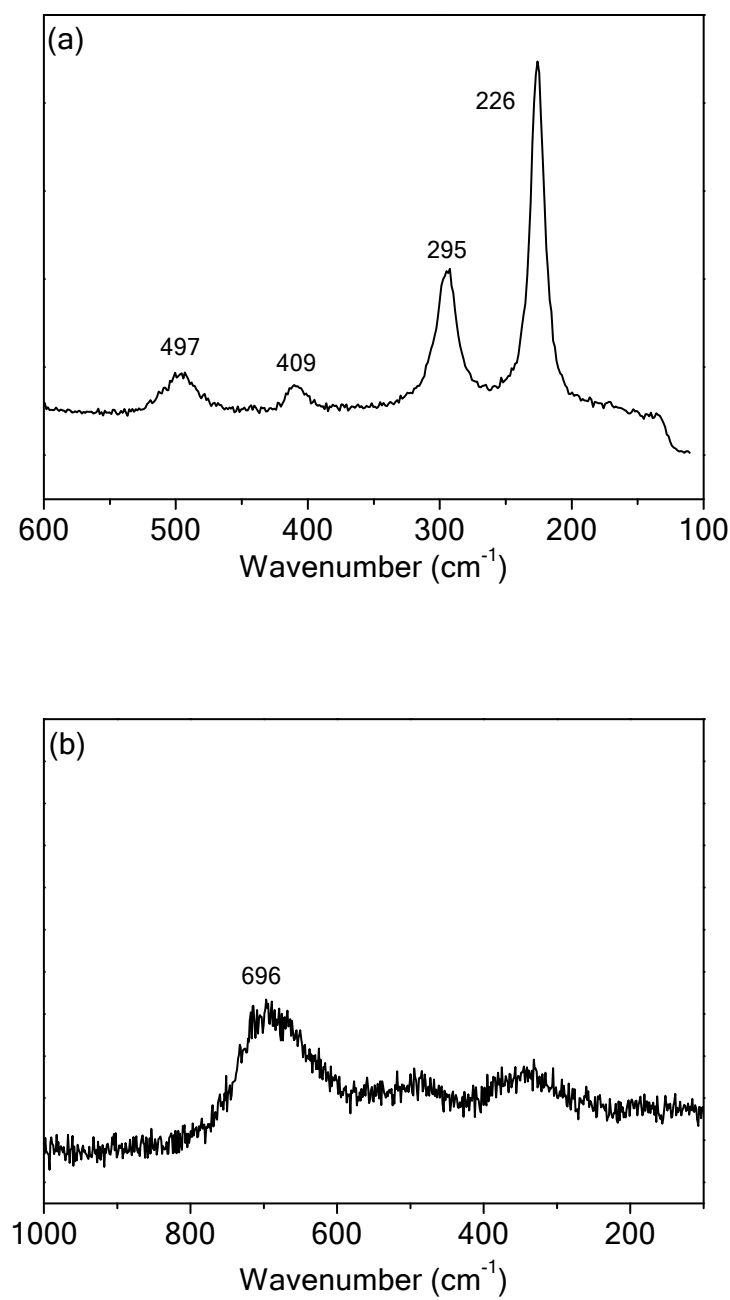

Figure S19. Raman spectra of (a) $\mathrm{Fe}_{2} \mathrm{O}_{3}$ and (b) $\mathrm{Fe}_{3} \mathrm{O}_{4}$.

\section{Thermal and optical property}

After the structural confirmation, we measured the thermal properties and optical properties of the poly(ionic liquid)s. Thermal gravity analysis (TGA) data showed that all of the magnetic compounds decomposed at about $300{ }^{\circ} \mathrm{C}$. Figure S21 showed the differential scanning calorimetry (DSC) measurements of magnetic monomer and polymer. It was confirmed three small broad peaks in DSC profiles on the heating scan of 
the measurement. And the three peaks were assigned to glass transition temperature $\left(T_{g}\right)$, liquid crystal transition temperature $\left(T_{i}\right)$ and melting temperature $\left(T_{m}\right)$. Compared with polymer, the small molecule magnetic ionic liquid TMBBDI[FeCl$\left.{ }_{4}\right]$ had much lower transition temperature. The melting temperature was $29{ }^{\circ} \mathrm{C}$ corresponding to the macro-phenomena that the TMBBDI$\left[\mathrm{FeCl}_{4}\right]$ shows a molten state at room temperature. While the transition temperature of polymer increased obviously owing to the rigidity main chain and high molecule weight. In consequence, at the temperature ranges, 20-30 ${ }^{\circ} \mathrm{C}$ for $\mathrm{TMBBDI}\left[\mathrm{FeCl}_{4}\right]$ and $95-133^{\circ} \mathrm{C}$ for PTMBBDI$\left[\mathrm{FeCl}_{4}\right]$ respectively, materials showed typical mesomorphic phenomena. In contrast, samples containing no biphenyl showed only typical thermal transition, a melting peak at $-26{ }^{\circ} \mathrm{C}$ of $\mathrm{HMI}\left[\mathrm{FeCl}_{4}\right]$ and glass transition temperature at $12{ }^{\circ} \mathrm{C}$ of $\mathrm{PHMI}\left[\mathrm{FeCl}_{4}\right]$.

Polarizing optical microscope observation was conducted in the transition ranges after DSC measurements. With temperature increasing at a $1 \mathrm{~K} / \mathrm{min}$ speed, a blue paillette of TMBBDI $\left[\mathrm{FeCl}_{4}\right]$ was observed in a temperature range $28-36^{\circ} \mathrm{C}$ associated with blue phases which were types of liquid crystal phases that appeared in a temperature range between a chiral nematic phase and an isotropic liquid phase (Figure S22). The blue phase temperature was a little higher than the melting point measured by DSC might be generated by hysteresis. ${ }^{7-9}$ Similar textures were also been record when observed PTMBBDI $\left[\mathrm{FeCl}_{4}\right]$ (Figure S22) while much weaker. The range of a blue phase was higher than monomer and appeared in $93-120^{\circ} \mathrm{C}$ which was consistent with the DSC results. 


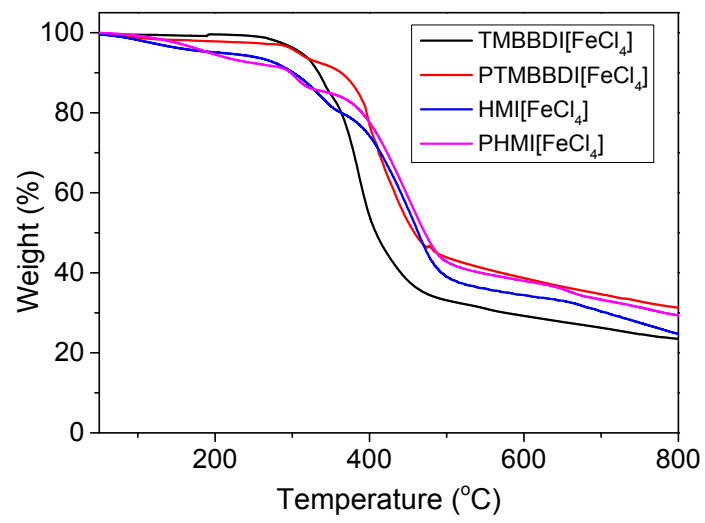

Figure S20. TGA diagrams of TMBBDI[FeCl 4 , PTMBBDI[FeCl $4, \mathrm{HMI}\left[\mathrm{FeCl}_{4}\right]$ and $\mathrm{PHMI}\left[\mathrm{FeCl}_{4}\right]$.
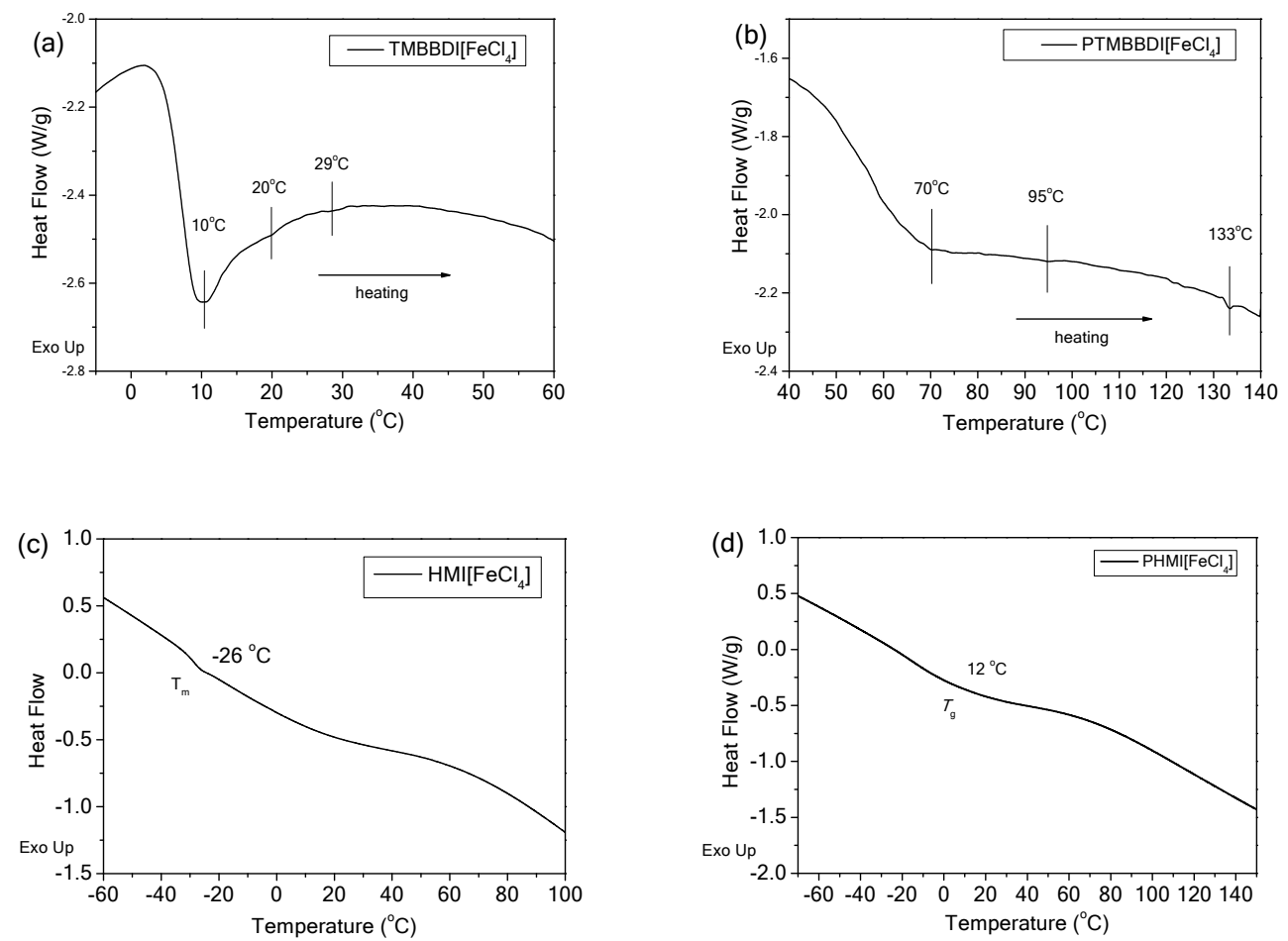

Figure S21. DSC diagrams of (A) TMBBDI[FeCl 4$]$, (B) PTMBBDI[FeCl 4$]$, (C) $\mathrm{HMI}\left[\mathrm{FeCl}_{4}\right]$ and (D) PHMI $\left[\mathrm{FeCl}_{4}\right]$ with a heating rate of $10{ }^{\circ} \mathrm{C} / \mathrm{min}$. 


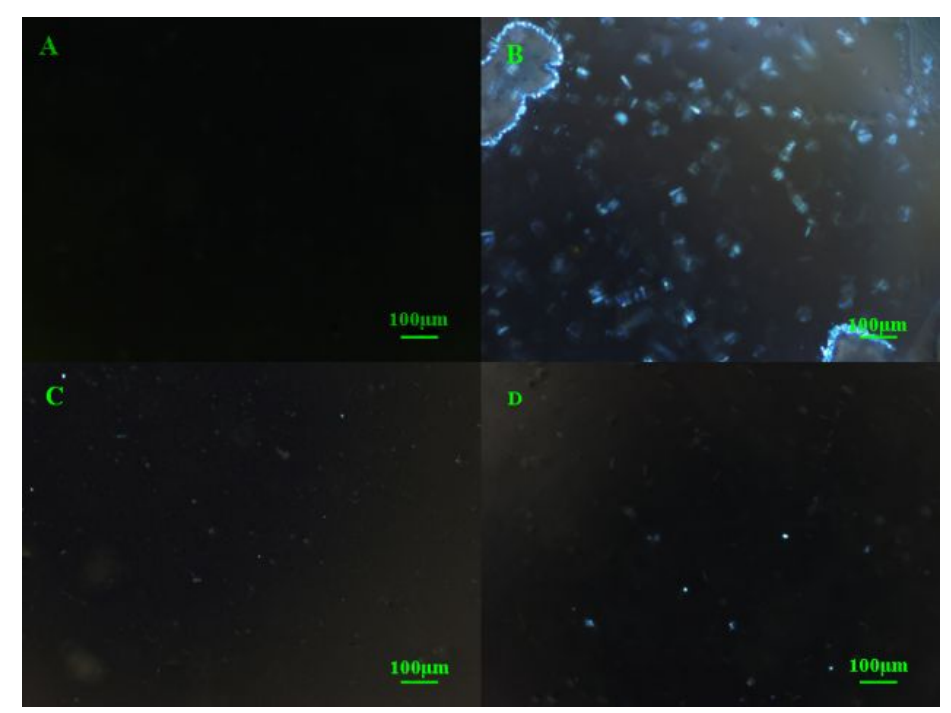

Figure S22. Polarized optical micrographs of TMBBDI[FeCl 4$]$ (A) dark field at $19{ }^{\circ} \mathrm{C}$; (B) blue phase texture at $30{ }^{\circ} \mathrm{C}$; and PTMBBDI $\left[\mathrm{FeCl}_{4}\right](\mathrm{C})$ dark field at $71{ }^{\circ} \mathrm{C}$; (D) blue phase texture at $116{ }^{\circ} \mathrm{C}$.

\section{XRD spectra and molecule Structure}

When the XRD spectrum of TMBBDI $\left[\mathrm{FeCl}_{4}\right]$ was expressed by the momentum transfer vector (q) (Figure S23) which $q$ satisfies the equation $q=(4 \pi / \lambda) \sin \theta,{ }^{10}$ the first three diffraction peaks approximately had 1:2:3 relationships, which were in agreement with q to $3 q$. It implied that a characteristic lamellar structure was developed. ${ }^{11}$ 


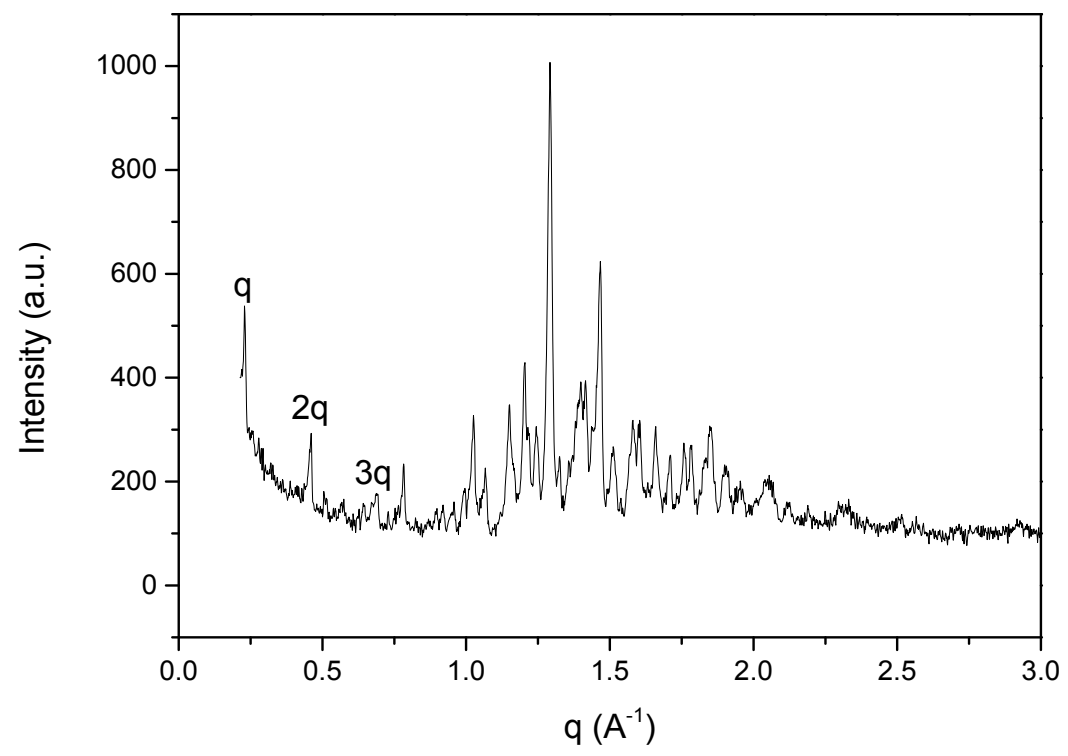

Figure S23. X-ray diffraction patterns (room temperature) of TMBBDI[ $\left.\mathrm{FeCl}_{4}\right]$ expressed by the momentum transfer vector $(\mathrm{q})$.

According to the result got through the XRD date, it was given an approximate molecular arrangement in Figure S24. It should be a single layer structure. 


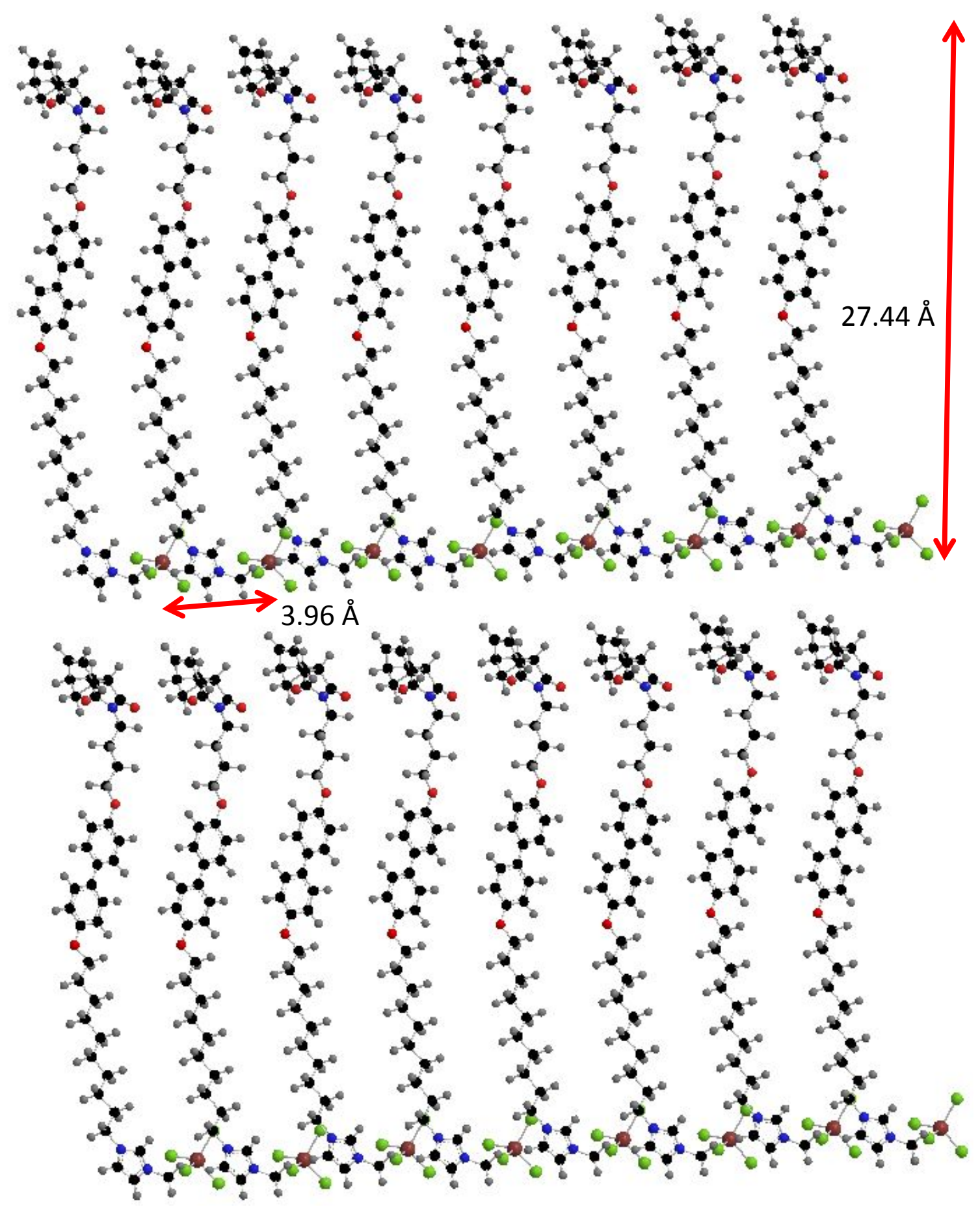

Figure S24. Possible molecular arrangement of TMBBDI $\left[\mathrm{FeCl}_{4}\right]$. 


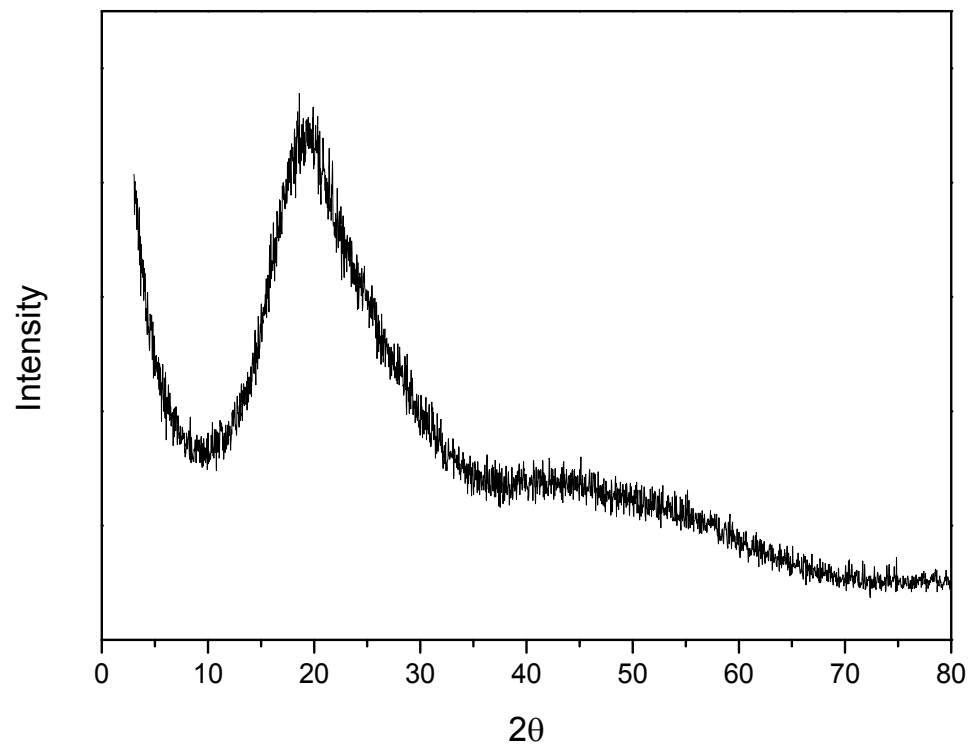

Figure S25. X-ray diffraction pattern (room temperature) of PTMBBDI[ $\left[\mathrm{FeCl}_{4}\right]$.

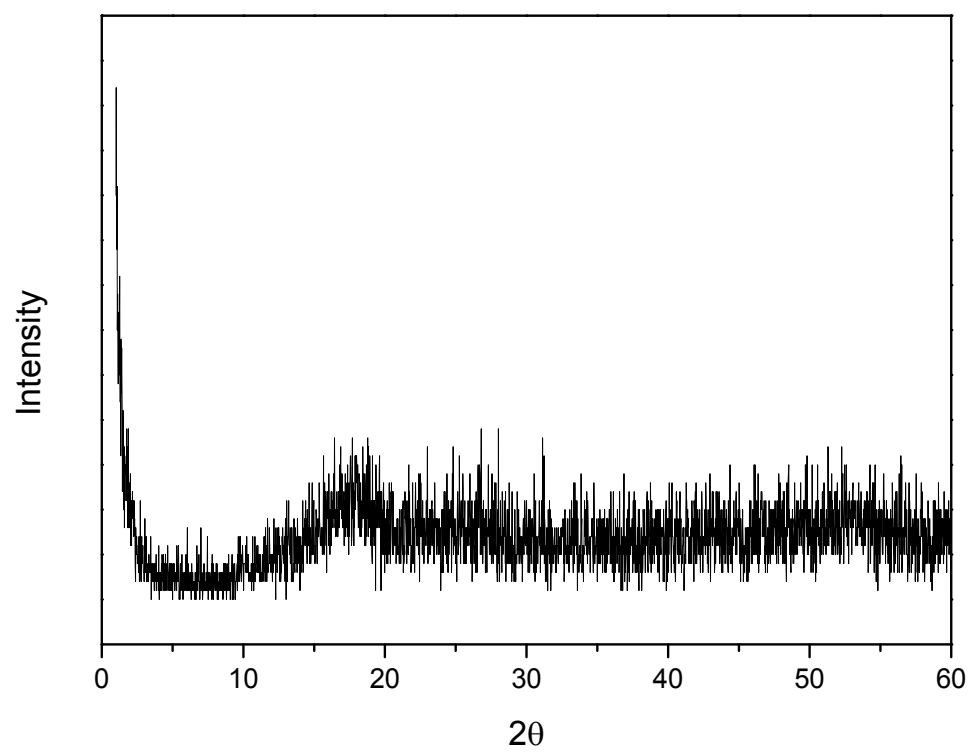

Figure S26. X-ray diffraction pattern (room temperature) of $\mathrm{HMI}\left[\mathrm{FeCl}_{4}\right]$. 


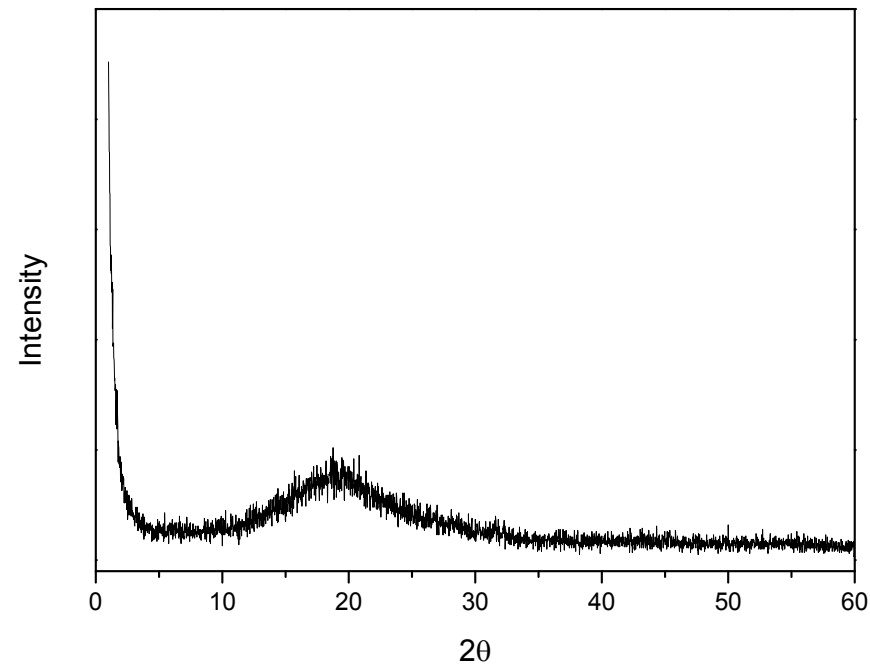

Figure S27. X-ray diffraction pattern (room temperature) of PHMI[FeCl 4 .

\section{Magnetic behavior}
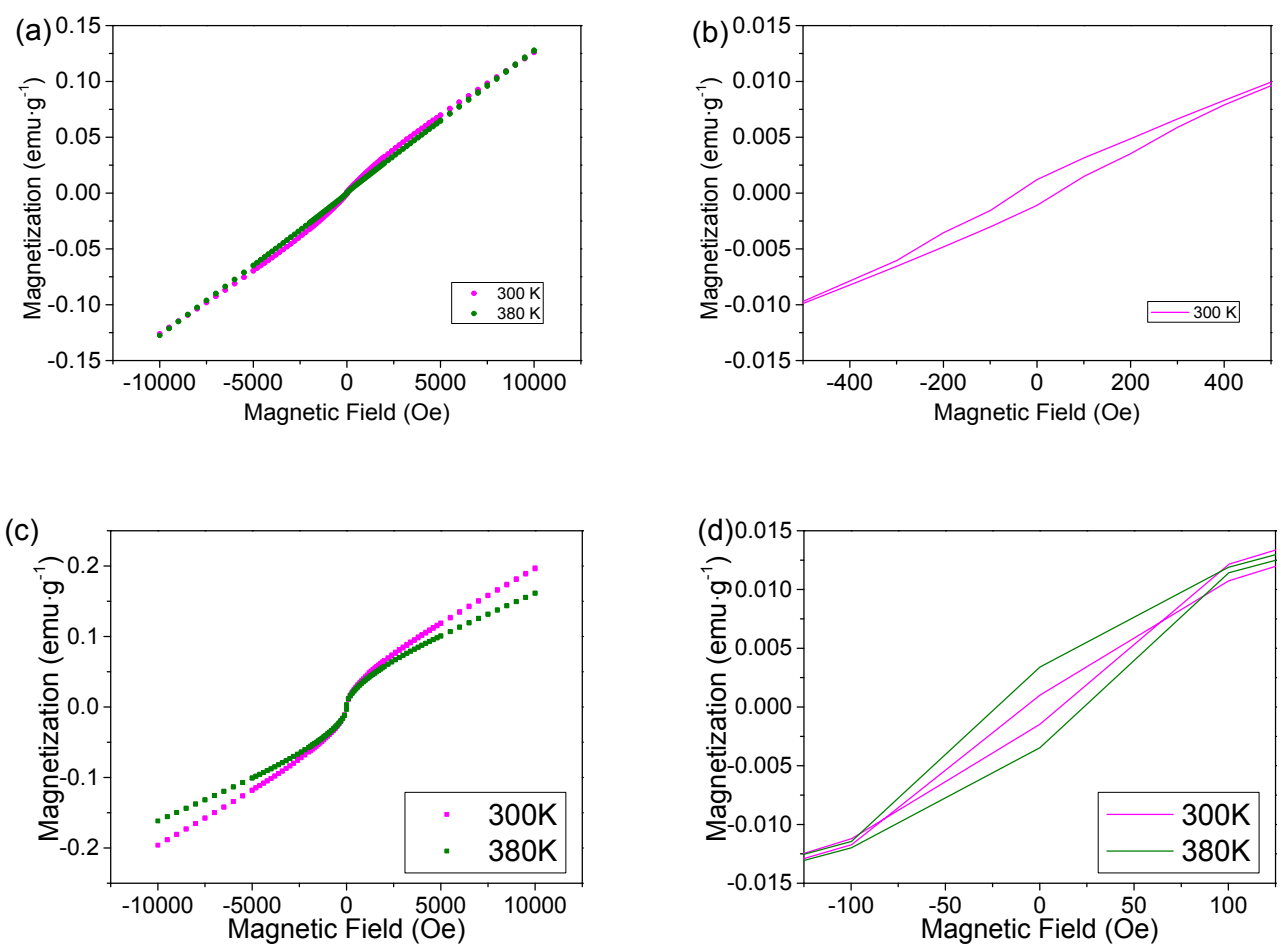

Figure S28. Enlarged M-H curves of (a), (b) TMBBDI[FeCl 4 and (c), (d) PTMBBDI[FeCl 4 at 300K and $380 \mathrm{~K}$. 


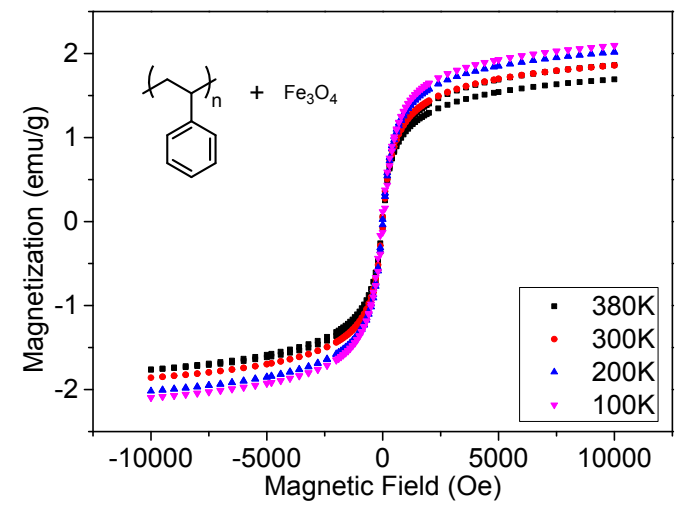

Figure S29. Enlarged M-H curves of ferric oxide doped styrene at different temperature (iron content was the same as TMBBDI[FeCl 4$], 6.79 \%$ ).
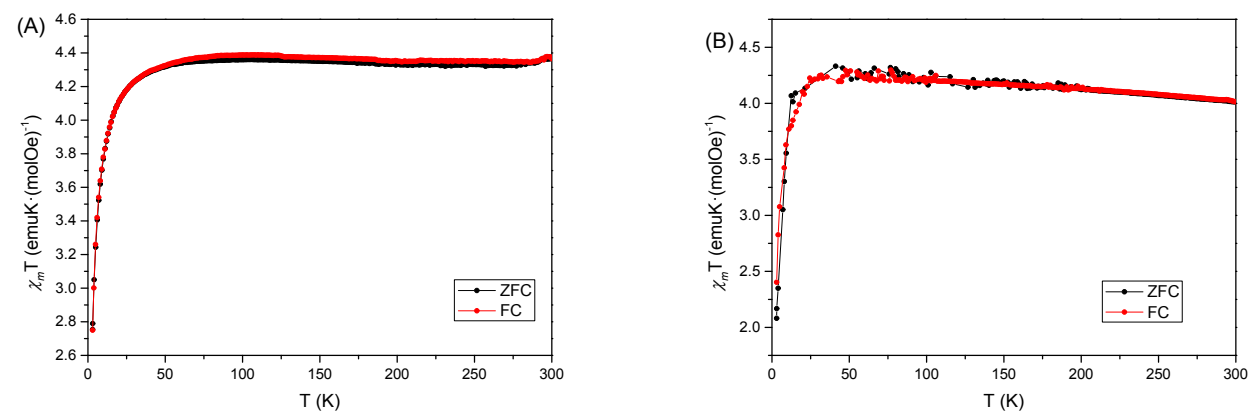

Figure S30. Temperature dependence of $\chi_{g} T$ for (A) $\mathrm{HMI}\left[\mathrm{FeCl}_{4}\right]$ and (B) $\mathrm{HMI}\left[\mathrm{FeCl}_{4}\right]$ at an applied magnetic field of $10 \mathrm{k}$ Oe.

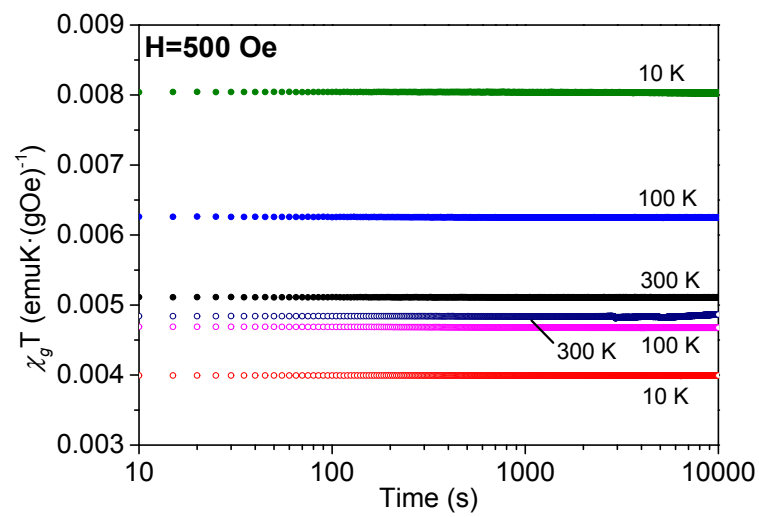

Figure S31. Time dependence of $\chi_{g} T$ for TMBBDI $\left[\mathrm{FeCl}_{4}\right]$ (solid circle) and $\mathrm{HMI}\left[\mathrm{FeCl}_{4}\right]$ (open circle) at an applied magnetic field of 500 Oe. 


\section{References}

(1) Ren, L.; Zhang, J.; Bai, X.; Hardy, C. G.; Shimizu, K. D.; Tang, C. Preparation of Cationic Cobaltocenium Polymers and Block Copolymers by "Living" Ring-Opening Metathesis Polymerization. Chem. Sci. 2012, 3, 580-583.

(2) Qiao,Y.; Zhao, Y.; Yuan, X.; Zhao, Y.; Ren, L. One-Dimensional Photonic Crystals Prepared by Self-Assembly of Brush Block Copolymers with Broad PDI. J. Mater. Sci. 2018, 53,16160-16168.

(3) Yu, X.; Mu, C.; Dai, D.; Yuan, X.; Zhang, K.; Ren, L. Well-Defined Magnetic Responsive Polymers Containing Ammonium $\mathrm{FeCl}_{4}$ from ROMP. Macromol. Chem. Phys. 2016, 217, 2700-2707.

(4) He, H.; Zhong, M.; Adzima, B.; Luebke, D.; Nulwala, H.; Matyjaszewski, K. A Simple and Universal Gel Permeation Chromatography Technique for Precise Molecular Weight Characterization of Well-Defined Poly(Ionic Liquid)s. J. Am. Chem. Soc. 2013, 135, 4227-4230.

(5) Wang, J.; Yao, H.; Nie, Y.; Zhang, X.; Li, J. Synthesis and Characterization of the Iron-Containing Magnetic Ionic Liquids. J. Mol. Liq. 2012, 169, 152-155.

(6) Cui, J.; Yang, S.; Zhang, J.; Zhao, S.; Yan, Y. A Novel Poly[(N-Vinylimidazole)-co-(1-Pyrenylmethyl Methacrylate)] Ferric Complex with Fluorescence and Superparamagnetism. RSC Adv. 2012, 2, 12224.

(7) Bukusoglu, E.; Wang, X.; Martinez-Gonzalez, J. A.; de Pablo, J. J.; Abbott, N. L. Stimuli-Responsive Cubosomes Formed from Blue Phase Liquid Crystals. Adv. Mater. 2015, 27, 6892-6898.

(8) Kikuchi, H.; Yokota, M.; Hisakado, Y.; Yang, H.; Kajiyama, T. Polymer-Stabilized Liquid Crystal Blue Phases. Nat. Mater. 2002, 1, 64.

(9) Gharbi, M. A.; Manet, S.; Lhermitte, J.; Brown, S.; Milette, J.; Toader, V.; Sutton, M.; Reven, L. Reversible Nanoparticle Cubic Lattices in Blue Phase Liquid Crystals. ACS Nano 2016, 10, 3410-3415.

(10) Smith, A. M.; Williams, R. J.; Tang, C.; Coppo, P., Collins, R. F., Turner, M. L.; Saiani, A.; Ulijn, R. V. Fmoc-Diphenylalanine Self Assembles to a Hydrogel via a Novel Architecture Based on $\pi-\pi$ Interlocked $\beta$-Sheets. Adv. Mater. 2008, 20, 37-41.

(11) Gu, W.; Huh, J.; Hong, S. W.; Sveinbjornsson, B. R.; Park, C.; Grubbs, R. H.; Russell, T. P. Self-assembly of symmetric brush diblock copolymers. ACS Nano 2013, 7, 2551-2558. 